\title{
Integrating truck arrival management into tactical operation planning at container terminals
}

\author{
Zhong-Zhen Yang, Ph.D., Professor \\ Transportation Management College, Dalian Maritime University, China \\ Gang Chen, Ph.D., Assistant Professor \\ Department of Mechanics and Production, Aalborg University, Denmark \\ Dong-Ping Song, Ph.D., Professor \\ School of Management, Plymouth University, the United Kingdom
}

\begin{abstract}
Truck arrival management (TAM) has been recognized as an effective solution to alleviate the gate congestion at container terminals. To further utilize TAM in improving the overall terminal performance, this study integrates TAM with the other terminal operations at a tactical level. An integrated planning model and a sequential planning model are presented to coordinate the major terminal planning activities, including quayside berth allocation, yard storage space allocation and TAM. A heuristic-based genetic algorithm is developed to solve the models. A range of numerical examinations are performed to compare two planning models. The result shows that: the integrated model can improve the terminal performance significantly from the sequential model alone, particularly when the gate capacity and the yard capacity are relatively low; whereas the sequential model is more efficient than the integrated model in terms of computational time.
\end{abstract}

Keywords: container terminal; integrated planning; truck arrival management; berth allocation; storage space allocation

\section{INTRODUCTION}

As an intermodal interface, marine container terminals serve vessels on the sea side and trucks/trains on the land side. Operating a container terminal involves many different decisions and they often interact with each other. Due to the multi-criteria nature, the complexity of operations, and the size of the operations management problem, it is extremely difficult to make the optimal decisions for the entire terminal system (Zhang et al., 2003). Traditionally, the whole system is decomposed into a set of sub-planning problems of manageable complexity. The sub-problems may be solved in a sequential fashion, in which the output of one sub-problem is treated as the input of another sub-problem. This sequential solution enables a clear hierarchy of decision making, but on the other hand, ignores the interrelations between the sub-problems and often leads to plans of poor overall quality (Bierwirth and Meisel, 2010). In order to find better planning decisions, it is necessary to integrate some of the sub-planning problems and optimize them simultaneously at a reasonable planning level, as mentioned by Stahlbock and Voss (2008) that "improved terminal performance cannot necessarily be obtained by solving isolated problems but by an integration of various operations connected to each other."

Many container terminals in Asia have a typical layout as shown in Fig. 1, which consists of three parts: the seaside area, the yard storage area and the landside area. The seaside area is the place where vessels are berthed and operated by quay cranes. The landside area, also called gate house, is the entrance and exit place for external trucks (XTs). Between the seaside and the landside areas is the storage yard, which stores inbound $(\mathrm{I} / \mathrm{B})$ and outbound $(\mathrm{O} / \mathrm{B})$ containers temporarily because there are time differences between vessel arrivals and land-carrier arrivals (Meisel, 2009). Typically the yard is divided into several blocks, which are laid out in parallel to

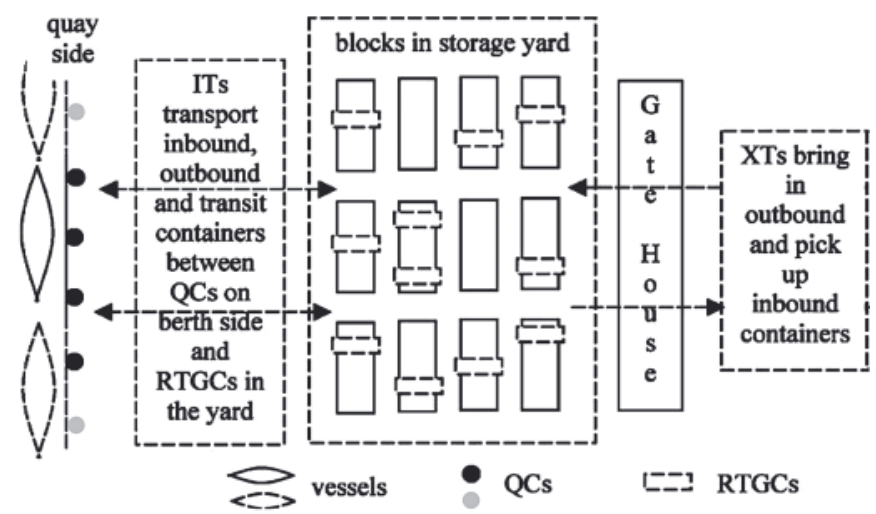

Fig. 1. A schematic diagram of a container terminal (Source: Zhang et al., 2003) 
the quay. The blocks are usually separated into two parts: the one on the seaside is for $\mathrm{O} / \mathrm{B}$ containers and the other on the landside is for $\mathrm{I} / \mathrm{B}$ containers.

In a container terminal, all the operations are originally triggered by the vessel arrival process, including $\mathrm{O} / \mathrm{B}$ container deliveries, vessel unloading/loading operations and I/B container pickups. Before a vessel arrives, the O/B containers are delivered into the terminal by XTs. An XT has to go through the gate check and then drives the container to the appointed block, where a yard crane (YCs) will unload the container from the truck and stack it onto the block. When the vessel is berthed, the quay cranes (QCs) discharge I/B containers from the vessel and load them on internal trucks (ITs). ITs provide transportation of containers between the QCs and the storage yard. After the unloading process, the QCs start to load the vessel with the $\mathrm{O} / \mathrm{B}$ containers that have already been in the yard. When both unloading and loading operations are finished, the vessel departs and the storage space previously occupied by the $\mathrm{O} / \mathrm{B}$ containers is released for future arriving $\mathrm{O} / \mathrm{B}$ containers. Meanwhile XTs start to pick up the I/B containers and deliver to customers.

The above terminal operations give rise to a series of operation planning problems at different levels, including berth allocation problem (BAP), QCs assignment, QCs scheduling, storage space allocation problem (SSAP), container location planning, YCs assignment, YCs scheduling, horizontal transport scheduling in yard, workforce management and gate management. Among the above, BAP, SSAP and gate management are the major planning activities dealing with the space usage of a container terminal. BAP is to determine berthing location and time for arriving vessels, and SSAP is to allocate storage space to each vessel for future arriving containers, with an aim to utilize terminal space efficiently and to make loading/unloading operations more efficiently.

Gate management generally facilitates truck entries into a terminal. At the major seaports long XTs queues occur very often at gate, which generate heavy air pollution and limit the terminal efficiency. To alleviate the gate congestion, terminal operators try two measures: reducing truck service time and managing XTs arrivals. Truck service time mainly depends on gate capacity and the number of yard cranes. Due to the high cost of yard cranes and the scarce land for gate capacity extension, it is not always possible to effectively reduce truck service time. Therefore truck arrival management (TAM) is receiving more and more attention. TAM tries to match the demand with the supply of XTs service by managing the truck arrival rate. There are different ways to do TAM, for example terminal appointment system, tariff and vessel dependent time windows (VDTWs). In a gate appointment system, the terminal operator announces the gate opening hours and hourly entry quotas through a web-based information system, and then the XTs make entry appointments in the information system. Tariff is also an effective method to move some traffic to non-peak times by charging higher entrance fees for peak time entries. Chen et al. (2011a) propose a two phase approach to find a desirable pattern of time varying tolls that leads to optimal XTs arrival pattern, by combining a fluid based queuing model and a toll pricing model. VDTWs involve partitioning truck arrivals into groups and assigning different time windows to the groups. The XTs entries related to a same vessel are grouped to share one specified time window. VDTWs are implemented in some terminals in Northern China, especially those having limited storage space because VDTWs is originally used to speed up container turnover. This paper focuses on VDTWs and its integration with other major terminal operation planning activities.
In order to better manage the space usage of container terminals, it is important to conduct all the three major planning activities, BAP, SSAP and TAM, in an integrated way. Since TAM is a relatively new topic in terminal operation research, the following interesting research questions arise: 1) How to integrate TAM with the other planning activities? 2) How to solve the integrated planning model? 3) In what situations the integration is more beneficial or less beneficial? The third question is based on the fact that the integrated model is more complicated and more difficult to solve, e.g. it may require more data and computational effort. This study tries to address these questions by developing an integrated planning model at the tactical level, covering BAP, SSAP and TAM. The tactical level is chosen for two reasons. First, tactical planning focuses on the space usage of a terminal over a medium term planning horizon, which represents a roll-over dynamic interval and provides a scheduling guidance for short-term operational activities. Second, tactical planning involves only a few major sub-planning problems, so the complexity of integration is manageable. In this study, the proposed integrated planning model takes the terminals in northern China as a prototype, where VDTWs is implemented to do TAM. To solve the proposed model, we develop a heuristics-based Genetic Algorithm (GA). Numerical experiments are conducted to compare the integrated planning model with its corresponding sequential planning model, in which the tactical BAP, SSAP and TAM are solved in a sequential fashion.

Our main contributions include: (i) we propose two models to coordinate three major planning activities for container terminal management at the tactical level including BAP, SSAP, and TAM. The first model is an integrated planning model which considers the two-way interactions between these planning activities. The second model is a sequential planning model, which is a natural development from traditional separate models; (ii) we develop heuristics-based GA algorithm to seek the solutions to two models so that the problem can be solved fairly efficiently; (iii) in the range of our experiments, it is found that the integrated model performs significantly better than the sequential model alone especially when the gate capacity and the yard capacity are relatively low; whereas the sequential model may fail to find a feasible solution; however, the sequential model has the advantage of much less computational time; (iv) our model can also be used to identify the lower and upper bounds of the yard capacity and the gate capacity for a given scenario.

\section{LITERATURE REVIEW}

There is a rich literature in the area of marine container terminal modelling. A few comprehensive reviews on terminal related operations research have been conducted, e.g. Stahlbock and Voss (2008), Steenken et al. (2004) and Vis and Koster (2003). Here, we only review the existing studies related to BAP, SSAP, TAM and their integration at the tactical planning level.

BAP is one of the most frequently addressed topics in the literature on container terminals. There are two main categories of BAP: the discrete operational BAP (Imai et al., 2001; 2003; Cordeau et al., 2005), and the continuous operational BAP (Imai et al., 2005; Guan and Cheung, 2004). Very few studies have been conducted on the tactical BAP problem. Moorthy and Teo (2006) address a continuous BAP problem at the tactical level, i.e. berth template design, which arises in transhipment container terminals. The problem concerns the allocation of favourite berthing locations (home berths) to vessels that call at the terminal based on a weekly schedule. 
Two procedures are proposed to build good and robust templates, which are then evaluated via numerical simulations. Ganji et al, (2010) proopse a GA-based algorithm to sovle continuous BAP problem. Giallombardo et al. (2010) integrate the discrete BAP problem and the quay crane assignment problem in transhipment container terminals at a tactical level. The objective is to maximize the quay crane utilization and minimize the container housekeeping costs. The problem is solved by a heuristic algorithm which combines Tabu search methods and mathematical programming techniques. To solve the discrete BAP more efficiently, de Oliveira et al. (2012) propose a hybrid Clustering Search method, which is found faster than the existing methods in the literature.

SSAP is another well addressed terminal operation planning problem. Regarding the SSAP for O/B containers, TalebIbrahimi et al. (1993) propose some methods to estimate the average space requirement and suggest a strategy of providing a temporary storage area for the containers that arrive before a designated storage space has been allocated for them. Zhang et al. (2003) consider the SSAP problem under the complex storage policy, which means I/B, O/B and transhipment containers are mixed at the block level. They attempt to balance the workload among different blocks to avoid possible bottlenecks in terminal operations. Kim and Park (2003) propose two heuristic algorithms to solve the SSAP for $\mathrm{O} / \mathrm{B}$ containers based on the duration-of-stay of containers and the sub-gradient optimization, respectively. Lee et al. (2007) propose a yard space allocation method for a transhipment hub port. They present an algorithm for assigning parts of blocks (called sub-blocks) to containers that are to be loaded (discharged) onto (from) a same vessel so as to minimize the congestion during the vessel handling operations. Bazzazi et al. (2009) propose a GA algorithm for a SSAP problem that is similar to the one in Zhang et al. (2003), aiming to minimize the variation in the handling workload across various blocks. Woo and Kim (2011) develop a method to determine the size of the storage space for $\mathrm{O} / \mathrm{B}$ containers in the initial stage of constructing container terminals. Chen and $\mathrm{Lu}$ (2010) propose a two stage method to solve the storage location assignment problem for $\mathrm{O} / \mathrm{B}$ containers. Regarding the SSAP for I/B containers, Kim and Kim (1999) propose mathematical models and solution procedures to optimally allocate storage space in the segregation strategy, with the aim of minimizing the expected total number of rehandles.

As mentioned previously, there are three common ways to handle TAM, i.e. terminal appointment system, tariff, and VDTWs. Here we only review the studies related to the VDTWs method. These studies mainly focus on two problems: truck arrival estimation and queue length estimation. Regarding the truck arrival estimation problem, Yang et al. (2010) analyze empirical data from a Chinese port where VDTW is employed, and find that truck arrivals for $\mathrm{O} / \mathrm{B}$ container drop-offs within a specific time window basically follow a Beta distribution. This finding makes it possible to predict truck arrivals at a terminal based on gate time window assignment for truck entries. Thereafter Chen and Yang (2010) address the time windows assignment problem to spread out the truck arrival peaks and develop a Genetic Algorithm to solve the problem. Regarding the queue length estimation problem, an empirical study, Guan and Liu (2009), finds that the gate service times follow an Erlang distribution with a parameter of four. Chen et al. (2011b) develop a non-stationary Exponential-Erlang queueing model to analyze a queueing system with Poisson arrival process and Erlang service process. Chen et al. (2011c) find that although the above queueing model may not theoretically match the VDTWs truck queueing system in terms of customer arrival process, it is practically acceptable to use the model to analyze such a system under the VDTWs control.

There have been a few studies addressing the integration of planning activities in container terminals. According to Geoffrion (1999), integration can be done either by a deep integration or by a functional integration. A functional integration is realized by a computational agenda that defines a sequence of sub-problems and the feedback loops between the sub-problems. Deep integration merges two sub-problems into a partial monolithic problem formulation (Bierwirth and Meisel, 2010). Deep integration has been widely used to merge BAP and QCs assignment into an integrated planning model. It was firstly introduced by Park and Kim (2003) and further investigated by Meisel and Bierwirth (2005), Imai et al. (2008), Giallombardo et al. (2010), Han et al. (2010) and Chang et al. (2010). For a comprehensive survey on this topic, we refer to Bierwirth and Meisel (2010).

An increasing number of tactical planning researches on terminal operations appeared in the last several years. Tactical planning deals with medium-term planning issues and provides an input to the operational planning phase. Cordeau et al. (2007) address the service allocation problem, a tactical problem arising in the yard management of a container transhipment terminal. They define a service as the sequence of ports visited by a vessel, where shipping companies usually ask for a dedicated specific yard area and a specific berth from a terminal. The objective is to minimize the volume of container rehandling operations inside terminal yards by optimizing the home berth for each service. The above mentioned Giallombardo et al. (2010) and Moorthy and Teo (2006) are the other existing studies on tactical terminal planning.

From the above literature review, it can be seen that the existing studies of integrated terminal planning focus on the seaside operations, for example combining the BAP and the SSAP problems. Moreover, most of these existing integration studies are conducted at the operational level, and only a few are at the tactical level. Because TAM is a relatively new topic in terminal operation research, to the best of our knowledge, there is no published research on integrating the TAM problem with the other planning problems. This paper tries to fill this gap.

\section{PROBLEM FORMULATION AND MATHEMATICAL MODEL}

\section{Problem Formulation}

For the tactical terminal operation planning, vessel arrival times and handling volumes are known to terminal operators from the negotiation with shipping lines. To utilize terminal space and resources, a terminal operator makes tactical decisions on the following issues: BAP, SSAP and TAM. According to the classification in Bierwirth and Meisel (2010), the BAP problem in this study is a discrete and dynamic one. The berth handling efficiency is assumed to depend on berth location, rather than the number of assigned quay cranes. In the terminal yard, the storage blocks are separated into zones, with around six or eight blocks in one zone. Each berth has an $\mathrm{O} / \mathrm{B}$ and an $\mathrm{I} / \mathrm{B}$ container zones in equal size lying parallel to it. The SSAP for O/B container storage is solved at the storage zone level, following the 'nearest location principle' proposed by Woo and Kim (2011), which requires 'the spaces that are assigned to a container vessel should be located as near as possible to the berthing position of the corresponding vessel'. The TAM for O/B containers adopts the VDTWs mechanism. At the gate, XTs are served on the principle of 'first come, first served' (FCFS). 
For simplicity, this study focuses on the O/B operations in these issues. The interaction between the $\mathrm{O} / \mathrm{B}$ and the $\mathrm{I} / \mathrm{B}$ operations is insignificant and can be neglected at the tactical operation planning level, because the two types of containers are operated either in separate spaces and/or during separate time periods. The objective of the tactical planning is to minimize of total vessel turn-around time in the planning horizon, which includes vessel waiting time for available berth, handling time and extra waiting time caused by gate congestion. There are some assumptions as below:

1. Both terminals and trucking companies provide $24 \times 7$ service, which is the case in China;

2. Each berth can service one vessel at a time without any physical or technical restrictions such as vessel draft and water depth;

3. Once moored, a vessel will remain in its location until all the handling is done, because it is costly to interrupt vessel handling process in practice;

4. Vessel handling time depends on the handling volume of the vessel and the handling efficiency of the assigned berth, as well as the distance between the vessel berthing location and the container storage location;

5. SSAP problem is solved at the storage zone level, and the container location problem is not under consideration in this tactical operation planning.

6. Yard equipments are sufficient and will not affect the gate capacity and the quay capacity. In other words, yard handlings are not considered in this model.

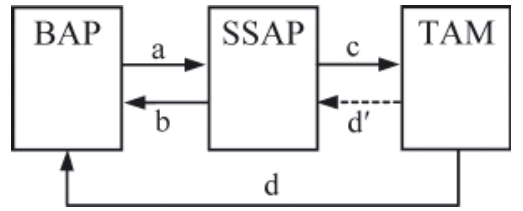

Fig. 2. The structure of the integrated tactical planning model

Based on the above description and assumptions, we develop an integrated tactical operation planning model by combining BAP, SSAP and TAM problems with the deep integration approach. A key issue of the deep integration approach is to identify the interrelations between the sub-problems. Fig. 2 shows the interrelations between BAP, SSAP and TAM in our integrated model. Interrelation ' $a$ ' represents that, when a vessel gets an assigned berthing time and location, SSAP is triggered to allocate storage space to the $\mathrm{O} / \mathrm{B}$ containers. The output of BAP is the input of SSAP. Interrelation ' $b$ ' represents that, the distance between the container storage location and the vessel berthing location influences on vessel handling time and hence the BAP plan. Interrelation 'c' represents that, when a storage space is assigned to a vessel, TAM is triggered to find a suitable time window from the available period of the storage space for the XTs entries. Interrelation ' $d$ ' can be linked to either BAP or SSAP. If linking to BAP, it represents the case that a vessel departs only after all the handling is completed, meaning the gate congestion directly leads to vessel handling delay. If linking to SSAP, as shown by the dashed arrow ' $\mathrm{d}$ ', it represents the case that a vessel always departs on schedule leaving the late containers in the yard for future pickup by a vessel (usually at next week), which means the gate congestion leads to longer container storage time. Both cases could happen in reality; we study the first one in this paper.

\section{Integrated planning VS sequential planning}

In this section, we use a simple example to illustrate the benefit of the integrated planning versus the sequential planning. For simplicity, the example focuses on the interrelation between
BAP and TAM. Suppose at one berth in a container terminal, there are two ships arriving at the same time (at hour 20), which raise a question of the berthing sequence. The berth is free when the ships arrive. Ship A will load 2,000 TEU from the terminal, and ship B will load 1,500 TEU. The available gate capacity is shown in Fig. 3: it increases from 0 to 200 truck/hour at hour 10, and decreases to 75 truck/hour at hour 20. The gate operation is managed with the VDTWs method, in which the terminal operator uses time windows to control truck arrivals. To make this example as small as possible, we make the following assumptions:

- Both ships have no unloading operations, i.e. no I/B container operations.

- The berth handling efficiency is 100TEU per hour.

- There is sufficient storage space in the yard, so no need to consider SSAP problem.

- The $\mathrm{O} / \mathrm{B}$ container arrivals will distribute evenly in a given time window, so the arrival process is not stochastic but deterministic. This means the truck queueing time can be estimated by simple fluid model, and there is no need for any queueing model.

- The time window for the trucks serving a ship will be closed when the ship arrives.

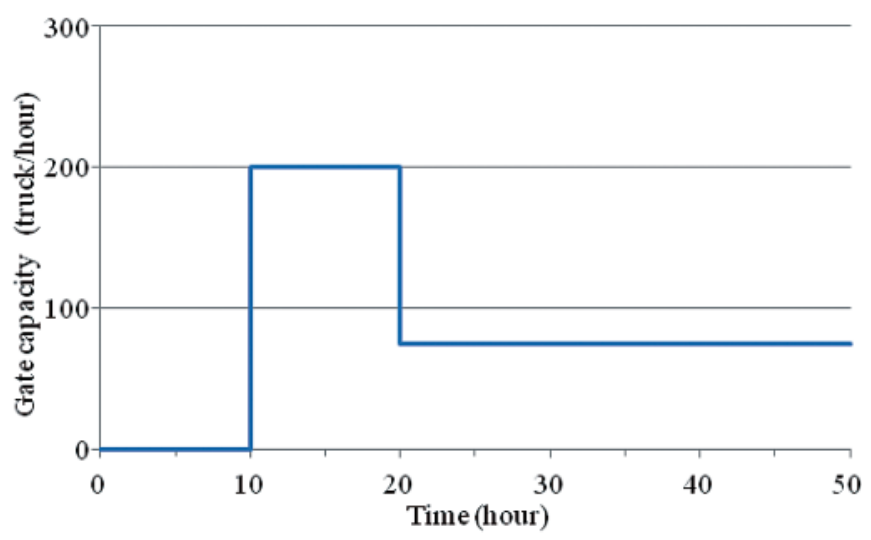

Fig. 3. The available gate capacity at the terminal

Since the SSAP is not considered, the solution for this example problem includes a berthing sequence and the starting points of the time windows for truck entries. This problem can be solved by either sequential planning or integrated planning. Sequential planning consist two steps, i.e. first, deciding on the berthing sequence, with the aim of minimizing the total ship waiting time, and second, deciding on the time window setting, with the aim of minimizing the total truck waiting time. The integrated planning solves the two problems simultaneously, aiming to minimize the total ship waiting time.

\section{Sequential planning approach}

The result of sequential planning is shown in Table 1. The procedure is described briefly here. The first step is to decide on the berthing sequence: obviously, putting ship B on berth before ship A, will lead to 15 hours ship waiting time, which is 5 hours less than putting ship A before ship B. Please note that this step does not consider the ship operation delay caused by gate congestion. The SSAP problem is skipped, because of sufficient storage space. Next step is to decide on the starting point of time windows: the best solution is to set both at hour 10 , which means the time windows for ship A and B are [10, $35]$ and $[10,20]$ respectively. In such a solution, the total truck waiting time is 7,500 hours. The truck queue is presented in Fig. 4. Due to the delay of the last O/B container (which will cause the ship departure delay of the same time length), the ship 
Tab. 1. The solutions of the sequential and the integrated planning

\begin{tabular}{|c|c|c|c|c|}
\hline & Berthing sequence & Time windows & Total ship waiting & Total truck waiting \\
\hline $\begin{array}{c}\text { Sequential } \\
\text { planning }\end{array}$ & B, A & $\begin{array}{r}{[10,35] \text { for ship A }} \\
{[10,20] \text { for ship B }}\end{array}$ & 24 hours & 7,500 hours \\
\hline $\begin{array}{c}\text { Integrated } \\
\text { planning }\end{array}$ & A, B & $\begin{array}{r}{[10,20] \text { for ship A }} \\
{[20,40] \text { for ship B }}\end{array}$ & 20 hours & 0 hour \\
\hline
\end{tabular}

A will be delayed for 4 hours and the ship B will be delayed for 5 hours. So in total, the ship waiting time is 24 hours.

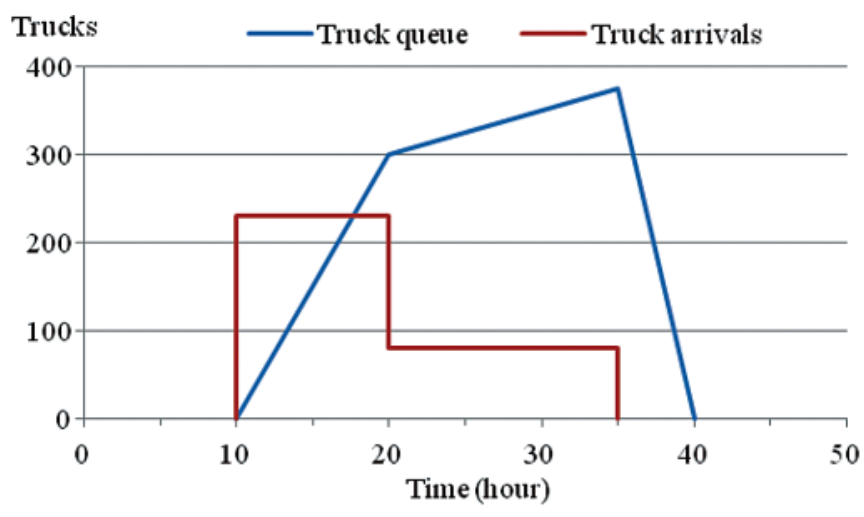

Fig. 4. The truck arrivals and queues at the terminal gate

\section{Integrated planning approach}

The result of integrated planning is also shown in Table 1. The best solution is: putting ship A on berth before ship B, and setting the time windows as $[10,20]$ and $[20,40]$ respectively. In this solution, the total ship waiting time is 20 hours, while the total truck waiting time is 0 because the gate capacity just fits with the truck arrival pattern.

Comparing the above results, we can see that the sequential planning misses the best solution due to the neglect of the interrelation between truck congestion and ship delay. While the integrated solution find the best solution, because it takes the interrelation into consideration.

\section{Integrated Planning Model}

In this section we present the integrated tactical planning model of terminal operations. All the input data, derived variables and decision variables are introduced first:

\begin{tabular}{|c|c|}
\hline $\begin{array}{l}\mathrm{J} \\
\mathrm{K} \\
\mathrm{P} \\
\mathrm{t} \\
\mathrm{A}_{\mathrm{i}} \\
\mathrm{V}_{\mathrm{i}} \\
\mathrm{r}_{\mathrm{i}} \\
\mathrm{B}_{\mathrm{k}} \\
\mathrm{G} \\
\mathrm{H}_{\mathrm{j}} \\
\beta \\
\mathrm{fM}_{1} \\
\mathrm{M}_{2} \\
\mathrm{~d}_{\mathrm{jk}} \\
\text { Derived variables } \\
\mathrm{T}_{\mathrm{i}}^{\mathrm{C}} \\
\mathrm{z}_{\mathrm{i}}^{\mathrm{W}} \\
\mathrm{z}_{\mathrm{i}}^{\mathrm{h}} \\
\mathrm{e}_{\mathrm{ti}} \\
\mathrm{d}_{\mathrm{j}} \\
\mathrm{N}_{\mathrm{t}} \\
\mathrm{p}_{\mathrm{it}} \\
\mathrm{q}_{\mathrm{t}} \\
\mathrm{w}_{\mathrm{t}} \\
\mathrm{T}_{\mathrm{i}}^{\mathrm{E}} \\
\\
\text { Decision variables } \\
\mathrm{x}_{\mathrm{ij}} \\
\mathrm{s}_{\mathrm{mi}}^{\mathrm{j}} \\
\mathrm{y}_{\mathrm{ik}} \\
\mathrm{T}_{\mathrm{i}}^{\mathrm{S}} \\
{ }_{\mathrm{i}}\end{array}$ & $\begin{array}{l}\text { The handling completion time and the departure time of vessel } \mathrm{i} \text {; } \\
\text { The waiting time of vessel } \mathrm{i} \text { (hour); } \\
\text { The handling time of vessel } \mathrm{i} \text { (hour); } \\
1 \text { if the time step } \mathrm{t} \text { is within the period }\left[\mathrm{T}_{\mathrm{i}}^{\mathrm{S}}, \mathrm{T}_{\mathrm{i}}^{\mathrm{C}}\right] \text {, otherwise } 0 \text {; } \\
\text { The distance between berth } \mathrm{j} \text { and the nearest storage zone, } \mathrm{d}_{\mathrm{j}}=\min \left(\mathrm{d}_{\mathrm{jk}}\right) \text {; } \\
\text { The number of trucks that arrive at time step } \mathrm{t} \text {; } \\
\text { The probability of a truck related to vessel } \mathrm{i} \text { arriving at time step } \mathrm{t} \text {; } \\
\text { The estimated queue length at the gate at time step } \mathrm{t} \text {; } \\
\text { The estimated waiting time of the trucks arriving at time step } \mathrm{t} \text { (hour); } \\
\text { The ending point of the time window assigned to vessel i for truck entries; } \\
1 \text { if vessel } \mathrm{i} \text { is assigned to berth } \mathrm{j} \text {, otherwise } 0 \text {; } \\
1 \text { if vessel } \mathrm{i} \text { is scheduled as the successor of vessel m at berth } \mathrm{j} \text {, otherwise } 0 \text {; } \\
1 \text { if the containers of vessel } \mathrm{i} \text { are stored in zone } \mathrm{k} \text {, otherwise } 0 \text {; } \\
\text { The starting point of the time window assigned to vessel } \mathrm{i} \text { for truck entries. }\end{array}$ \\
\hline
\end{tabular}


The objective of the integrated planning problem is to minimize the total waiting and handling time of all vessels in the planning horizon as follows:

$$
\min Z=\sum_{i \in \mathrm{I}}\left(z_{i}^{\mathrm{w}}+\mathrm{z}_{\mathrm{i}}^{\mathrm{h}}\right)
$$

Subject to:

$$
\begin{aligned}
& \mathrm{z}_{\mathrm{i}}^{\mathrm{h}}=\sum_{\mathrm{j} \in \mathrm{J}} \sum_{\mathrm{k} \in \mathrm{K}} \mathrm{x}_{\mathrm{ij}} \mathrm{y}_{\mathrm{ik}}\left(\mathrm{M}_{1}+\frac{\mathrm{d}_{\mathrm{jk}}}{\mathrm{dj}} \times \frac{\mathrm{V}_{\mathrm{i}}}{\mathrm{H}_{\mathrm{j}}}\right) \quad \forall \mathrm{i} \in \mathrm{I} \\
& \mathrm{z}_{\mathrm{i}}^{\mathrm{w}}=\max \left(0, \sum_{\mathrm{j} \in \mathrm{J}} \sum_{\mathrm{m} \in \mathrm{I}} \mathrm{x}_{\mathrm{ij}} \mathrm{S}_{\mathrm{mi}}^{\mathrm{j}} \mathrm{T}_{\mathrm{m}}^{\mathrm{c}}-\mathrm{A}_{\mathrm{i}}\right)+\mathrm{w}_{\mathrm{T}_{\mathrm{i}}^{\mathrm{E}}} \forall \mathrm{i} \in \mathrm{I} \\
& \mathrm{T}_{\mathrm{i}}^{\mathrm{C}}=\mathrm{A}_{\mathrm{i}}+\mathrm{z}_{\mathrm{i}}^{\mathrm{W}}+\mathrm{z}_{\mathrm{i}}^{\mathrm{h}} \quad \forall \mathrm{i} \in \mathrm{I} \\
& \mathrm{T}_{\mathrm{i}}^{\mathrm{E}}=\mathrm{A}_{\mathrm{i}}+\mathrm{z}_{\mathrm{i}}^{\mathrm{W}}-\mathrm{w}_{\mathrm{T}_{\mathrm{i}}^{\mathrm{E}}} \quad \forall \mathrm{i} \in \mathrm{I} \\
& \mathrm{w}_{\mathrm{t}}=\frac{\mathrm{q}_{\mathrm{t}}+\mathrm{q}_{\mathrm{t}-1}}{2 \times \mathrm{G}} \quad 1 \leq \mathrm{t} \leq \mathrm{P} \\
& \mathrm{q}_{\mathrm{t}}=\mathrm{B}-\operatorname{PSFFA}\left(\mathrm{q}_{\mathrm{t}-1}, \mathrm{~N}_{\mathrm{t}}, \mathrm{G}\right) 1 \leq \mathrm{t} \leq \mathrm{P} \\
& \mathrm{N}_{\mathrm{t}}=\sum_{\mathrm{i} \in \mathrm{I}} \frac{\mathrm{p}_{\mathrm{it}} \mathrm{V}_{\mathrm{i}} \mathrm{r}_{\mathrm{i}} \beta}{\mathrm{f}} \quad 1 \leq \mathrm{t} \leq \mathrm{P} \\
& p_{i t}=\left\{\begin{array}{l}
\frac{\int_{a}^{b} u^{0.29}(1-u)^{2.25} d u}{\int_{0}^{1} u^{0.29}(1-u)^{2.25} d u} \\
0
\end{array}\right.
\end{aligned}
$$

where:$$
a=\frac{t-T_{i}^{S}}{T_{i}^{E}-T_{i}^{S}}, b=\frac{t-T_{i}^{S}+1}{T_{i}^{E}-T_{i}^{S}}
$$$$
\text { if: }
$$$$
\mathrm{t} \in\left[\mathrm{T}_{\mathrm{i}}^{\mathrm{S}}, \mathrm{T}_{\mathrm{i}}^{\mathrm{E}}\right]
$$$$
\forall \mathrm{i} \in \mathrm{I}, 1 \leq \mathrm{t} \leq \mathrm{P}
$$

others

$$
\begin{gathered}
\sum_{\mathrm{i} \in \mathrm{I}} \mathrm{x}_{\mathrm{ij}} \mathrm{z}_{\mathrm{i}}^{\mathrm{h}} \leq \mathrm{P} \quad \forall \mathrm{j} \in \mathrm{J} \\
\sum_{\mathrm{j} \in \mathrm{J}} \mathrm{x}_{\mathrm{ij}}=1 \quad \forall \mathrm{i} \in \mathrm{I} \\
\sum_{\mathrm{m} \in \mathrm{I}} \mathrm{s}_{\mathrm{mi}}^{\mathrm{j}} \leq 1 \quad \forall \mathrm{i} \in \mathrm{I}, \forall \mathrm{j} \in \mathrm{J} \\
\sum_{\mathrm{m} \in \mathrm{I}} \sum_{\mathrm{i} \in \mathrm{I}} \mathrm{s}_{\mathrm{mi}}^{\mathrm{j}}=\sum_{\mathrm{i} \in \mathrm{I}} \mathrm{x}_{\mathrm{ij}}-1 \quad \forall \mathrm{j} \in \mathrm{J} \\
\sum_{\mathrm{t}=1}^{\mathrm{P}} \mathrm{e}_{\mathrm{ti}}=\mathrm{T}_{\mathrm{i}}^{\mathrm{C}}-\mathrm{T}_{\mathrm{i}}^{\mathrm{S}} \quad \forall \mathrm{i} \in \mathrm{I} \\
\sum_{\mathrm{i} \in \mathrm{I}} \mathrm{y}_{\mathrm{ik}} \mathrm{V}_{\mathrm{i}} \mathrm{r}_{\mathrm{i}} \mathrm{e}_{\mathrm{ti}} \leq \mathrm{B}_{\mathrm{k}} \quad \forall \mathrm{k} \in \mathrm{K}, 1 \leq \mathrm{t} \leq \mathrm{P}
\end{gathered}
$$

$$
\begin{gathered}
\sum_{\mathrm{k} \in \mathrm{K}} \mathrm{y}_{\mathrm{ik}}=1 \quad \forall \mathrm{i} \in \mathrm{I} \\
\mathrm{T}_{\mathrm{i}}^{\mathrm{C}}-\mathrm{P} \leq \mathrm{T}_{\mathrm{i}}^{\mathrm{S}} \leq \mathrm{T}_{\mathrm{i}}^{\mathrm{E}}-\max \left(\mathrm{M}_{2}, \frac{\mathrm{V}_{\mathrm{i}} \mathrm{r}_{\mathrm{i}}}{\mathrm{fG}}\right) \quad \forall \mathrm{i} \in \mathrm{I} \\
\mathrm{x}_{\mathrm{ij}} \in\{0,1\} \quad \forall \mathrm{i} \in \mathrm{I}, \forall \mathrm{j} \in \mathrm{J} \\
\mathrm{s}_{\mathrm{mi}}^{\mathrm{j}} \in\{0,1\} \quad \forall \mathrm{i} \in \mathrm{I}, \forall \mathrm{m} \in \mathrm{I}, \forall \mathrm{j} \in \mathrm{J} \\
\mathrm{y}_{\mathrm{ik}} \in\{0,1\} \quad \forall \mathrm{i} \in \mathrm{I}, \forall \mathrm{k} \in \mathrm{K} \\
\mathrm{e}_{\mathrm{ti}} \in\{0,1\} \quad \forall \mathrm{i} \in \mathrm{I}, 1 \leq \mathrm{t} \leq \mathrm{P}
\end{gathered}
$$

Equation (2) calculates the handling time of vessel $i$ at berth $\mathrm{j}$ when the containers are stored in the storage area $\mathrm{k}$, here $\mathrm{M}_{1}$ is the mooring time of a vessel. Equation (3) calculates the waiting time due to terminal gate congestion $\left(\mathrm{w}_{\mathrm{T}}\right)$ and the waiting time of vessel i for the availability of the assigned berth. Equation (4) calculates the expected handling completion time of vessel $\mathrm{i}$, considering the influence of yard operations and gate congestion. Equation (5) calculates the ending point of gate time window i. Note it is assumed that the time window assignment will not be influenced by the vessel delays caused by gate congestion; otherwise it will become a circular cause and consequence. Equation (6) calculates the average waiting time of the trucks arriving at time step t. Equation (7) calculates the queue length at gate at time step $t$ with the non-stationary queueing model proposed by Chen et al. (2011b), for simplicity here we quote the queueing model with its name 'B-PSFFA' instead of its complicated equations. Equation (8) calculates the number of trucks arriving at terminal gate at time step t. Based on the Beta distribution from Yang et al. (2010), Equation (9) calculates the probability of a truck related to vessel i arriving at the terminal gate at time step $t$.

Constraint (10) ensures that the total handling workload (hours) of each berth will not exceed the berth service capacity. Constraint (11) ensures every vessel must be served at some berth. Constraints (12) and (13) represent that in the berth plan any vessel has at most one immediate successor, and the total number of such succession relations at one berth equals to the number of vessels minus one. Constraint (14) ensures that every vessel gets a storage space reserved for its containers from the beginning of the time window to the vessel handling completion. Constraint (15) ensures that, at any time step, the storage demand in any storage zone does not exceed the storage capacity. Constraint (16) ensures that the storage space reserved for a vessel must be in one storage zone. Constraint (17) means that each time window must be long enough for the related trucks to enter the gate and also not shorter than the minimum time window length, meanwhile the starting point should not be earlier than the vessel handling completion time in the previous planning period according to practical experience.

\section{ALGORITHM SOLUTION}

Solving the integrated planning problem in (1) (21) is complicated and difficult, because four sets of decisions have to be optimized simultaneously, including berthing position of each vessel, the vessels' berthing sequence, yard storage space allocation to each vessel, and time window assignments for XTs entries. This optimization model is a nonlinear integer problem, which is NP-hard. To compromise the computational complexity with the solution quality, we propose a heuristicbased GA to solve the integrated planning model. The GA part in the algorithm is used to simultaneously optimize the vessel berthing positions and time window assignment for 
XTs entries, i.e. $\mathrm{x}_{\mathrm{ij}}$ and $\mathrm{T}_{\mathrm{i}}^{\mathrm{S}}$. The heuristic part consists of two heuristic rules (denoted as A and B). Given a profile of $\mathrm{x}_{\mathrm{ij}}$ from the GA part, Heuristic A is used to find the optimal vessel berthing sequences at each berth, i.e. $\mathrm{s}_{\text {mi }}^{\mathrm{j}}$; and then Heuristic B is used to allocate yard storage space to the containers of each vessel, i.e. $\mathrm{y}_{\mathrm{ik}}$. The adopted GA is illustrated in Section 4.1, and two heuristics are explained in Section 4.2 and Section 4.3 respectively. Section 4.4 introduces the wrap-around effect of periodical operation plans, which is needed in every single solution generation.

\section{GA Algorithm}

The proposed GA algorithm is designed to optimize two sets of decision variables $\mathrm{x}_{\mathrm{ij}}$ and $\mathrm{T}_{\mathrm{i}}^{\mathrm{S}}$. However, instead of directly using them as a chromosome in the GA, we introduce another set of variables $\left\{b_{i}\right\}$, where $b_{i}$ is the berthing position of vessel $i$. The chromosome of the GA consists of $b_{i}$ and $T_{i}{ }^{S}$, as shown in Fig. 5. Note that $b_{i}$ can be converted into $x_{i j}$ using Equation (22). Using $b_{i}$ instead of $x_{i j}$ can significantly simplify the solution representation and reduce the algorithm search space.

\begin{tabular}{|c|c|c|c|c|c|}
\hline 1 & 2 & 3 & & $\mathrm{I}$ & $\leftarrow$ Vessel index \\
\hline $\mathrm{b}_{1}$ & $\mathrm{~b}_{2}$ & $\mathrm{~b}_{3}$ & $\ldots$ & $\mathrm{b}_{\mathrm{I}}$ & $\leftarrow$ Berth number \\
\hline $\mathrm{T}_{\mathrm{i}}^{\mathrm{S}}$ & $\mathrm{T}_{\mathrm{i}}^{\mathrm{S}}$ & $\mathrm{T}_{\mathrm{i}}^{\mathrm{S}}$ & $\ldots$ & $\mathrm{T}_{\mathrm{i}}^{\mathrm{S}}$ & $\leftarrow$ Starting point of time window \\
\hline
\end{tabular}

Fig. 5. The chromosome structure in the GA

$$
\begin{gathered}
\mathrm{x}_{\mathrm{ij}}= \begin{cases}1, & \text { if } \mathrm{j}=\mathrm{b}_{\mathrm{i}} \\
0, & \text { others }\end{cases} \\
\mathrm{F}_{\mathrm{k}}=\frac{\max (\mathrm{Z})}{\mathrm{Z}_{\mathrm{k}}}
\end{gathered}
$$

The outline of the entire GA procedure is as follows:
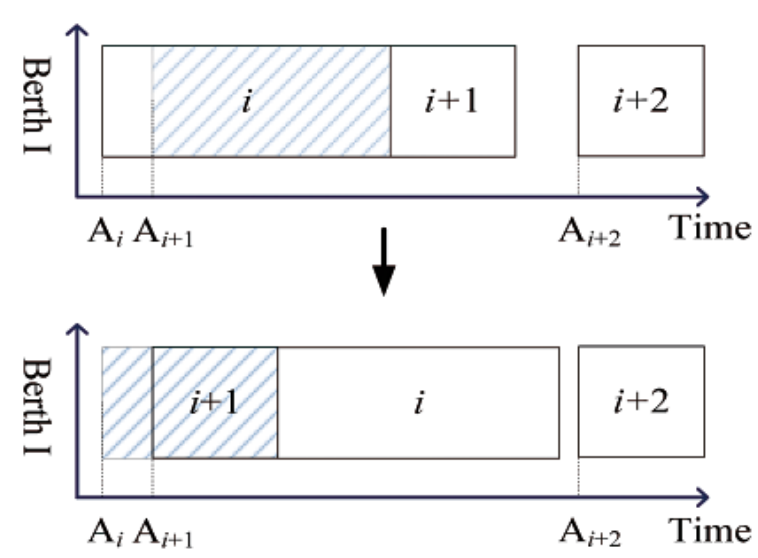

Fig. 7. Swapping berthing sequences in BAP planning

\section{Heuristic $A$}

Heuristic $\mathrm{A}$ is an iterative procedure designed to optimize $\mathrm{s}_{\mathrm{mi}}^{\mathrm{j}}$ based on $\mathrm{x}_{\mathrm{ij}}$. Given a profile of vessels at a specific berth, Heuristic A assigns $\mathrm{s}^{\mathrm{j}}{ }_{\mathrm{mi}}$ preliminarily based on the FCFS principle. Since the FCFS rule does not promise an optimal sequence, Heuristic A modifies $\mathrm{s}_{\mathrm{mi}}{ }_{\mathrm{i}}$ by swapping the berthing sequences of two neighbouring vessels, when a reduction of the total vessel waiting time can be realized. An example is shown in Fig. 7: the shadow area illustrates the vessel waiting time, which can be reduced by swapping the berthing sequences of vessel $i$ and vessel $i+1$. The swapping operation is repeated following the rule shown in Fig. 8, which ensures that all pairs of neighbouring vessels are checked and the final sequence is optimal.

\footnotetext{
Step.1 Initialization: generating an initial population in two ways:

1) importing the obtained solutions from the sequential planning model if any;

2) randomly generating a solution in the following rule: to generate each $b_{i}$, randomly select two berths and choose the one with fewer handling workload; convert $b_{i}$ into $x_{i j}$ using Equation (22); assign $\mathrm{s}_{\text {mi }}^{j}$ based on $x_{i j}$ with Heuristic $\mathrm{A}$; assign $\mathrm{y}_{\mathrm{ik}}$ based on $\mathrm{x}_{\mathrm{ij}}$ with Heuristic $\mathrm{B}$; lastly randomly generate $\mathrm{T}_{\mathrm{i}}^{\mathrm{S}}$ under the constraint of Equation (17).

Step.2 Evaluation: evaluate the initialized solutions and give higher probabilities to good solutions for survival with Equation (23), where $\mathrm{F}_{\mathrm{k}}$ is the fitness value of individual $\mathrm{k}$.

Step.3 Selection: use the roulette wheel method to select some solutions out for later breeding.

Step.4 Crossover: use the two-point crossover operator to produce an offspring.

Step.5 Mutation: to increase the variability of the population, randomly change the gene value of $b_{i}$ of each individual with the mutation ratio; convert $\mathrm{b}_{\mathrm{i}}$ into $\mathrm{x}_{\mathrm{ij}}$ using Equation (22); assign $\mathrm{s}_{\mathrm{mi}}{ }_{\mathrm{i}}$ based on $\mathrm{x}_{\mathrm{ij}}$ with Heuristic A; assign $y_{i k}$ based on $x_{i j}$ with Heuristic $B$; lastly randomly change the bits of $\mathrm{T}_{\mathrm{i}}^{\mathrm{S}}$ under the constraint of Equation (17) with the mutation ratio.

Step.6 Evaluation: evaluate the objective values of the offspring solutions.

Step.7 Reinsert: put two generations together and delete duplicate solutions if any, and give higher probabilities to good solutions for survival with Equation (23), where $\mathrm{F}_{\mathrm{k}}$ is the fitness value of individual $\mathrm{k}$. Select the top $20 \%$ solutions with Elitism Strategy and allow the others survive randomly.

Step. 8 Termination: stop, if the number of iteration reaches the pre-defined number; otherwise go to Step.3.
}

Fig. 6. The GA algorithm for the integrated planning model 


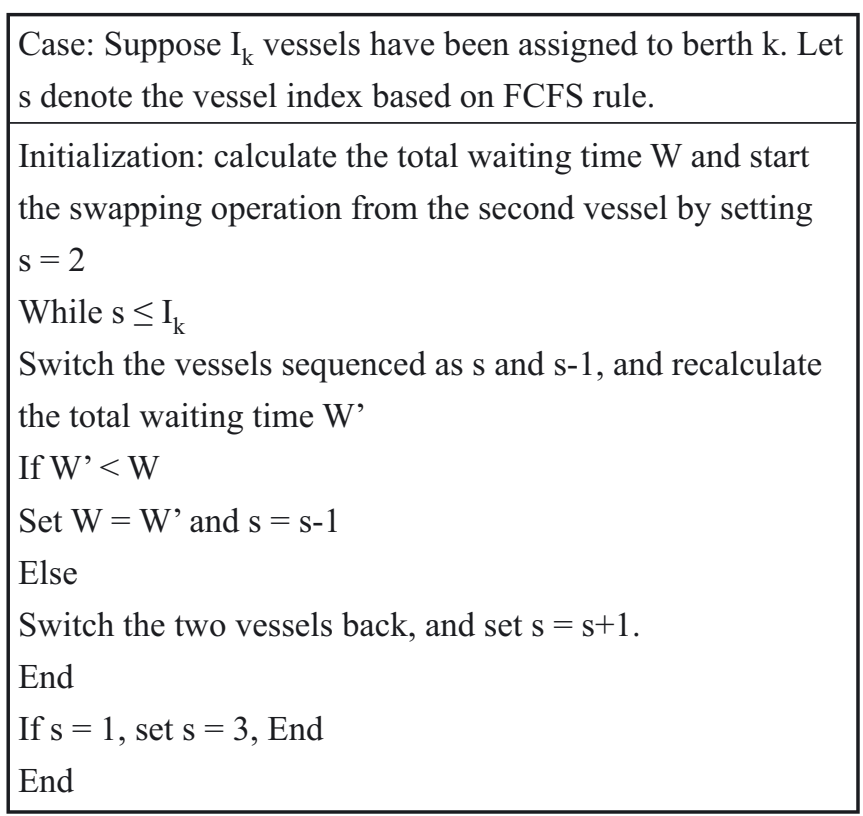

Fig. 8. Heuristic A for assigning vessel berthing sequences

\section{Heuristic B}

Heuristic B is the procedure designed to optimize $y_{i k}$ based on $\mathrm{x}_{\mathrm{ij}}$. Since locating containers far from the vessel berthing position will lead to long handling time, preliminarily the 'nearest location first' principle is used, i.e. allocate the closest storage space to a vessel (Woo and Kim, 2011). Then we use Equation (15) to check that whether the minimal storage demand in a storage zone exceeds the storage supply at any time step. Minimal storage demand refers to the demand whenever $\mathrm{T}_{\mathrm{i}}^{\mathrm{S}}$ is set as its latest possible starting point $\mathrm{T}_{\mathrm{i}}^{\mathrm{E}}-\max \left(\mathrm{M}_{2}, \frac{\mathrm{V}_{\mathrm{i}} \mathrm{r}_{\mathrm{i}}}{\mathrm{fG}}\right)$. If the maximum of minimal storage demand exceeds the supply in any storage zone, Heuristic $\mathrm{B}$ is used to modify $\mathrm{y}_{\mathrm{ik}}$.

\section{Wrap-around Effect}

The wrap-around effect refers to the backward and forward effect of a periodical plan on the neighbouring periods, which is equivalently wrapped around back to the current planning period. The wrap around effect was introduced to solve the tactical BAP problem by Moorthy and Teo (2006). Fig. 10 illustrates the basic idea to deal with this effect, taking the BAP planning as an example. In Fig. 10, a rectangle represents the berthing time and the berthing position of a vessel and a shadow area represents a vessel's waiting time before berthing. The
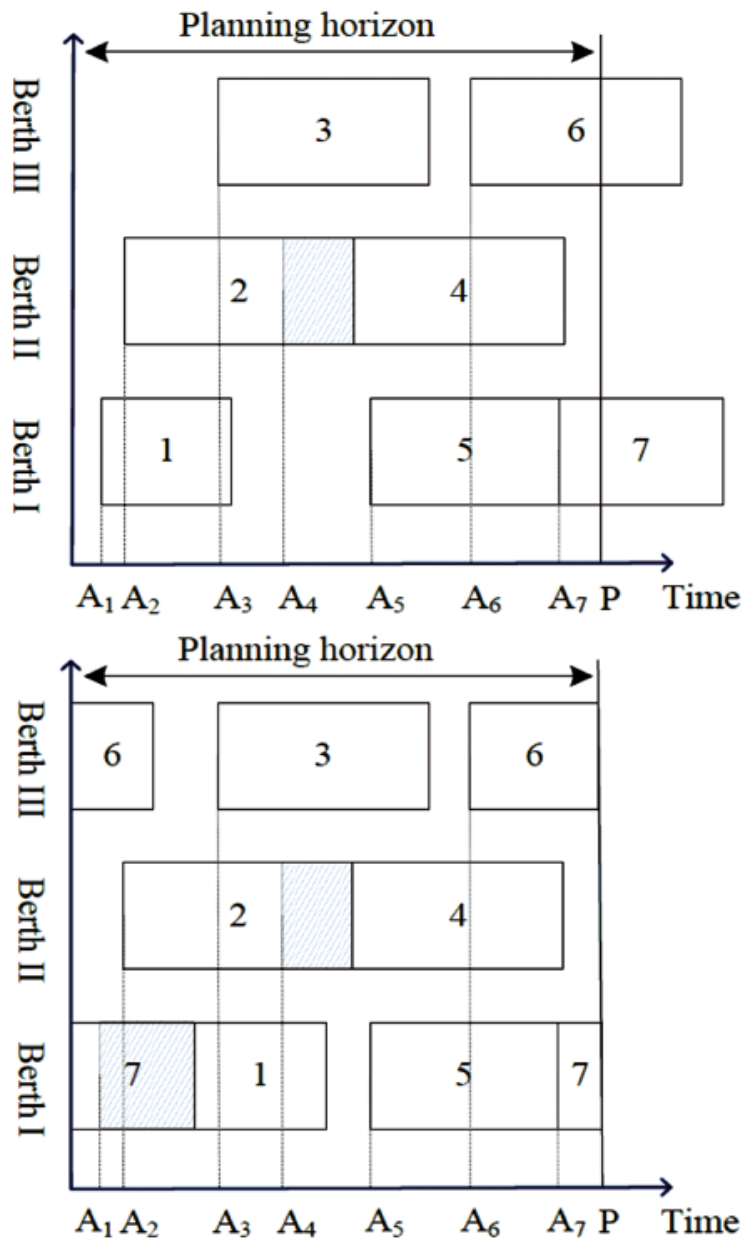

Fig. 10. Wrap around effect on BAP planning (the left is before wrapping and the right is after wrapping)

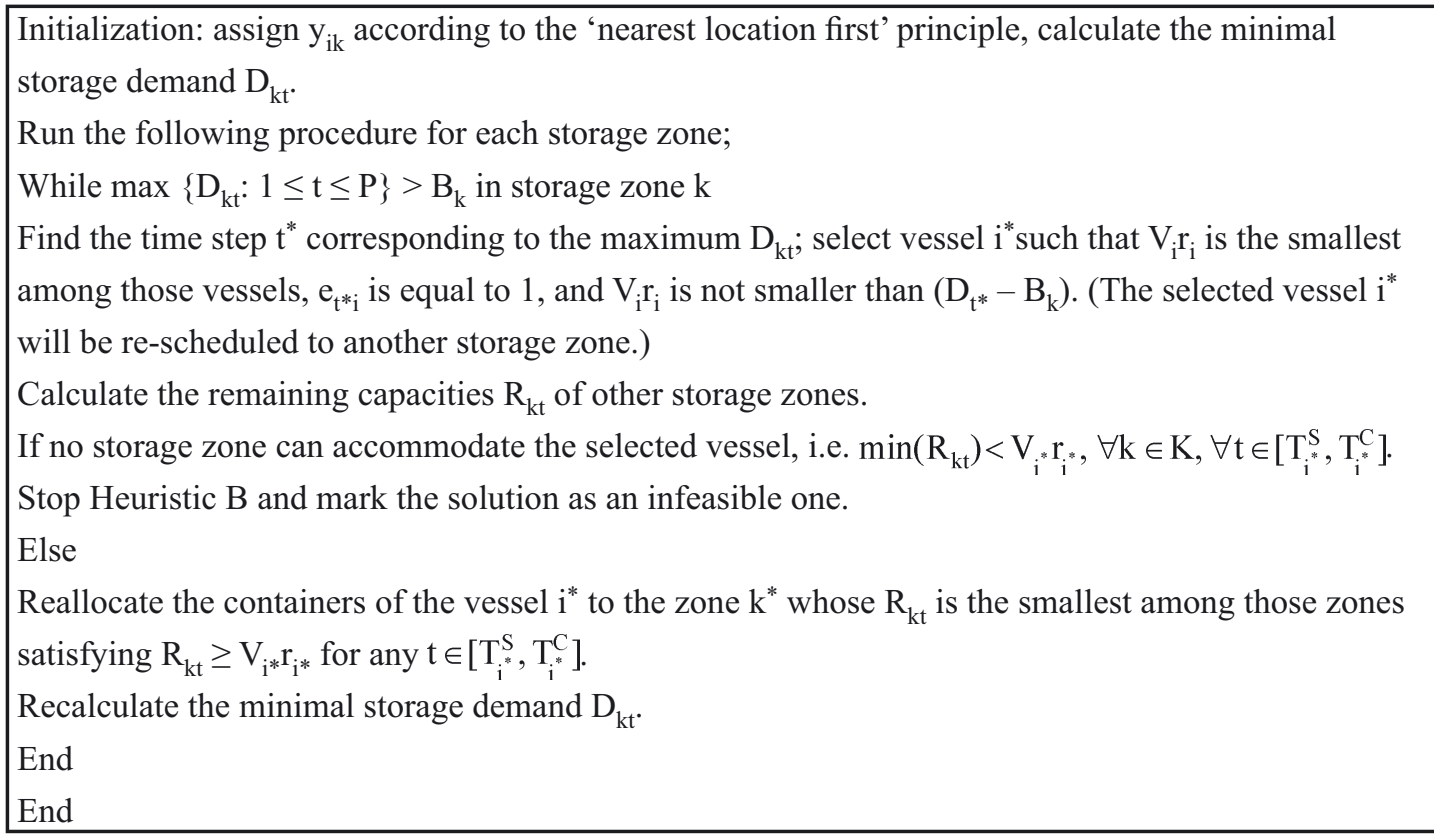

Fig. 9. Heuristic $B$ for allocating yard storage space 
handling operations of vessel 6 and vessel 7 go beyond the planning horizon, so they should be wrapped around back to the beginning of the planning horizon. As a consequence of wrapping vessel 7 around, the berthing time of vessel 1 is postponed causing a new shadow area. The idea shown in Fig. 10 can be realized by Equation (24) and (25): the first one can modify the time variables, for example time step t; the second can modify the variables indexed by time step, for example $\mathrm{p}_{\mathrm{it}}$.

$$
\begin{aligned}
& a^{\prime}= \begin{cases}a-P & \text { if } a>P \\
a+P & \text { if } a \leq 0\end{cases} \\
& a_{t}^{\prime}=a_{t}+a_{(t+P)}+a_{(t-P)}
\end{aligned}
$$

The above two equations can handle most of the variables in our problem, except for some conditional variables, such as $\mathrm{T}_{\mathrm{i}}^{\mathrm{C}}$ and $\mathrm{q}_{\mathrm{t}}$. These conditional variables are often indexed by time or refer to time, and their values at a (time) point highly depend on the previous ones. Wrapping such a conditional variable back will make a calculation circle, which is hard to find the right starting/cut point. In order to solve this problem, we need to make a feasibility test before wrapping a variable. The feasibility test concerns the relationship between demand and supply. Taking $\mathrm{T}_{i}{ }^{\mathrm{C}}$ as example, if the total demand (vessel handling time) exceeds the total supply (quay service hours) within a planning horizon, it will be infeasible to wrap around the conditional variable $\left(\mathrm{T}_{i}^{\mathrm{C}}\right)$. If the total demand (vessel handling time) does not exceed the total supply (quay service hours) within a planning horizon, the conditional variables $\left(\mathrm{T}_{\mathrm{i}}^{\mathrm{C}}\right)$ can be wrapped around. The wrap around operation can be done by running the wrapped loop only twice, starting from any (time) point with a hypothetical minimal value (mostly zero).

\section{NUMERICAL EXPERIMENTS}

The previous sections have addressed the questions 'how to integrate tactical terminal operations planning' and 'how to solve the integrated model'. This section focuses on the third question 'in what situations the integrated planning model should be used'. We will answer this question by comparing the integrated planning model with a sequential planning model through numerical experiments.

\section{Sequential Planning Model}

As mentioned in the literature review, there are adequate existing studies on each single part of the container terminal system, so it is relatively straightforward to construct a sequential planning model. The sequential model can be regarded as a simple way to handle the interaction between different terminal planning activities. However, as there is no feedback from one end to the other, the coordination may be limited. For the simplicity of article structure, the detailed sequential planning model is presented in Appendix A, and here we only introduce the model framework briefly. In the sequential model, the three sub-planning models are placed in the top-down direction, as shown in Fig. 11. These sub-planning models will be solved in a sequential fashion: the output of BAP is used as the input of SSAP, and the output of SSAP is used as the input of TAM.

The BAP sub-model here is similar to the one in Moorthy and Teo (2006) in terms of the wrap around effect and the tactical level of modelling. While the BAP model in Moorthy and Teo (2006) is in a continuous case, our BAP sub-model is a discrete one. We solve the BAP sub-model with a GA algorithm combined with Heuristic A.

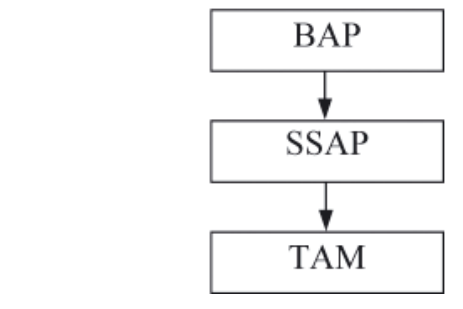

Fig. 11. The structure of the sequential tactical planning for terminal operations

The SSAP sub-model has two tasks: 1) allocating yard space to vessels for container storage and 2) defining a range of the starting point for each time window, which will be used as an input in the TAM sub-model in order to make sure the obtained time window assignment satisfying the storage space constraint. The first task can be completed with Heuristic B following the 'nearest location first' principle proposed by Woo and Kim (2011). After allocating storage space, the second task is to optimize the earliest possible starting points of the time windows aiming to maximize the yard utilization rate, i.e. the number of containers multiplied by their longest possible storage time. With respect to this objective, we find that the starting point of a time window must be a vessel's handling completion time in the previous period, which releases some storage space. This means the size of the search space in the second task is $I_{k}$ to the power of $I_{k}$, where $I_{k}$ is the number of vessels whose containers are allocated to storage zone $\mathrm{k}$. The second task can be solved with a search algorithm, for example GA or Tabu.

Given the range of each time window's starting point, the TAM sub-model tries to find the optimal set of starting points to minimize the total truck waiting time, which may lead to vessel delays. A similar TAM sub-model with slightly different objective function is proposed by Chen and Yang (2010) and solved with a GA algorithm, so we adopt their algorithm solution to solve the TAM sub-model in this study.

After solving the three sub-models separately, it is necessary to evaluate the three obtained sub-plans as a whole. This is because the sequential planning model neglects some interrelations between the sub-models, for example truck congestion at the terminal gate may delay yard operations and vessel operations; storing containers far away from the berthing position of the correspondent vessel may increase handling time thereby delay the vessel departure. By introducing the interrelations into the combination of the obtained sub-plans, we will get a complete solution of the sequential planning model.

The obtained solution of the sequential planning model is later used as the input of the initialization operation for the integrated planning model in order to speed up the searching process.

\section{Numerical Experiments}

Suppose a hypothetical seaport terminal has five berths, ten yard zones and a gate house of four entries lanes. This hypothetical container terminal is proposed based on a real terminal. The analysis horizon for tactical operation planning is one week. Regarding the inputs, the vessel interarrivals are randomly generated following an Exponential distribution with an average interval of three hours, and the handling volumes of these vessels are generated following 
a uniform distribution with an average of 1,100 TEU. The XTs arrivals are managed by the terminal operator with the VDTWs method, so a truck arrival time follows the Beta distribution within the corresponding time window. For simplicity, the handling efficiencies of the berths are assumed to be identical of $100 \mathrm{TEU} /$ hour, and the average ratio of $\mathrm{O} / \mathrm{B}$ handling volume is assumed as $50 \%$ for every vessel. The vessel mooring time and the shortest length of a time window are assumed as one hour and six hours respectively. In this hypothetical terminal, all the containers are delivered by XTs.

In the experiment, we conduct 130 instances with different yard capacities and gate capacities as shown in Table 2 . The total yard capacity is evenly distributed over the yard zones, half of which are used for $\mathrm{O} / \mathrm{B}$ container storage. The integrated and the sequential planning models are coded and solved using Matlab 7.8. The mutation ratio, the crossover ratio, the population, and the iteration number are set $0.02,0.7,100$ and 5,000 in the GA for the integrated planning model, and as $0.05,0.7,100$ and 1,000 in the GA for the sequential planning model. These GA parameters are selected based on some pilot experiments.

\section{Result Analysis}

Table 3 shows the total vessel turn time (in hours) of the sequential planning model in the instances. For each instance, the result is presented in a range covering the top 20 obtained solutions. This is because the best solution obtained from the sequential planning model is not always the best overall plan, due to the neglect of the interrelations between the submodels. So taking top- $n$ solutions can better represent the sequential model performance than the 'nominal' best solution. The results of the top-n solutions in an instance form a result range. Across all the instances, the result range varies about 3.5 percent from the correspondent mean. Table 4 shows the total vessel turn time (in hours) of the integrated planning model in the instances.

It can be seen that the integrated planning model outperform the sequential model significantly when the gate capacity and the yard capacity are relatively low, although their difference diminishes as the gate or the yard capacity increases (compared to the lower bounds of the result ranges from the sequential model). The sequential planning model cannot find feasible solutions in the instances with low yard capacity, e.g. when the total yard capacity is less than 40,000 TEUs. However, the integrated planning model can handle all instances, except the ones with the lowest yard capacity of 16,000 TEU. This indicates that the bottleneck constraint of the yard capacity could be relaxed through the integrated planning. On the other hand, the results show that 20,000 TEU (corresponding to $24 \%$ of the total quay crane handling capacity, which is 84,000 TEU per week) is the minimal required yard capacity to serve the given demand in this experiment. Similarly, the minimal required gate capacity to serve the given demand in this experiment is 204 entries per hour.

Tab. 2. Parameters for the test instances

\begin{tabular}{|c|c|c|}
\hline Parameter & Name & Value \\
\hline $\mathrm{I}$ & Number of Vessels & 56 \\
\hline $\mathrm{V}_{\mathrm{i}}$ & Handling volume $[\mathrm{min}, \max ](\mathrm{TEU})$ & {$[10,2200]$} \\
\hline$\Sigma \mathrm{B}_{\mathrm{k}}$ & Total Yard capacity $\left(\times 10^{3} \mathrm{TEU}\right)$ & $16,20,24,28,32,36,40,44,48,56,64,72,84$ \\
\hline $\mathrm{G}$ & Total Gate capacity (entries/hour) & $200,204,208,212,220,230,240,260,300,400$ \\
\hline $\mathrm{f}$ & Truck loading factor (TEU/truck) & 1.8 \\
\hline
\end{tabular}

Tab. 3. The results of the sequential planning model

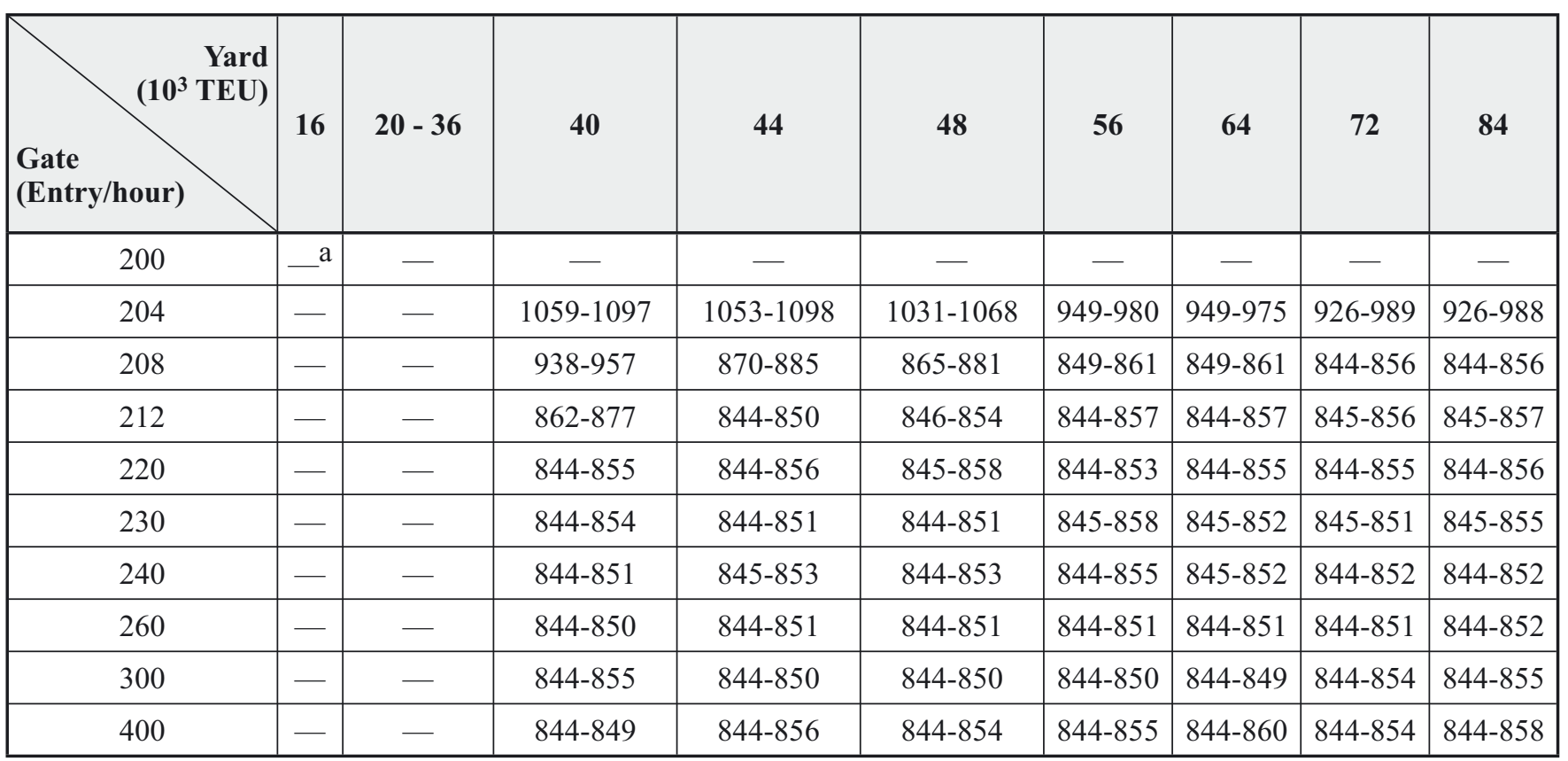

$\mathrm{a}-$ represents infeasible solution. 
Tab. 4. The results of the integrated planning model

\begin{tabular}{|c|c|c|c|c|c|c|c|c|c|c|c|c|c|}
\hline $\begin{array}{r}\text { Yard } \\
\left(10^{3} \mathrm{TEU}\right) \\
\text { (Entry/hour) }\end{array}$ & 16 & 20 & 24 & 28 & 32 & 36 & 40 & 44 & 48 & 56 & 64 & 72 & 84 \\
\hline 200 & $-^{\mathrm{a}}$ & - & - & - & - & - & - & - & - & - & - & - & - \\
\hline 204 & - & 1180 & 1099 & 1045 & 991 & 986 & 983 & 983 & 972 & 926 & 926 & 926 & 926 \\
\hline 208 & - & 955 & 913 & 880 & 854 & 846 & 846 & 846 & 844 & 844 & 844 & 844 & 844 \\
\hline 212 & - & 937 & 901 & 865 & 844 & 844 & 844 & 844 & 844 & 844 & 844 & 844 & 844 \\
\hline 220 & - & 900 & 878 & 851 & 844 & 844 & 844 & 844 & 844 & 844 & 844 & 844 & 844 \\
\hline 230 & - & 872 & 866 & 847 & 844 & 844 & 844 & 844 & 844 & 844 & 844 & 844 & 844 \\
\hline 240 & - & 860 & 856 & 844 & 844 & 844 & 844 & 844 & 844 & 844 & 844 & 844 & 844 \\
\hline 260 & - & 850 & 845 & 844 & 844 & 844 & 844 & 844 & 844 & 844 & 844 & 844 & 844 \\
\hline 300 & - & 844 & 844 & 844 & 844 & 844 & 844 & 844 & 844 & 844 & 844 & 844 & 844 \\
\hline 400 & - & 844 & 844 & 844 & 844 & 844 & 844 & 844 & 844 & 844 & 844 & 844 & 844 \\
\hline
\end{tabular}

a - represents infeasible solution.

Tab. 5. The comparison of detailed results from two planning models

\begin{tabular}{|c|c|c|c|c|c|c|c|c|c|}
\hline \multicolumn{2}{|c|}{ Instance } & \multicolumn{3}{|c|}{ The Sequential Planning Model } & \multicolumn{3}{|c|}{ The Integrated Planning Model } \\
\hline $\begin{array}{c}\text { Yard } \\
\left(\mathbf{1 0} \mathbf{3}^{\mathbf{T}} \mathbf{T E U}\right)\end{array}$ & $\begin{array}{c}\text { Gate (entry/ } \\
\text { hour) }\end{array}$ & $\mathbf{z 1}$ & $\mathbf{z 2}$ & $\mathbf{z 3}$ & $\mathbf{Z}$ & $\mathbf{z 1}$ & $\mathbf{z 2}$ & $\mathbf{z 3}$ & $\mathbf{Z}$ \\
\hline \multirow{4}{*}{} & 200 & 844 & 0 & $-{ }^{\mathrm{a}}$ & - & - & - & - & - \\
\cline { 2 - 11 } & 204 & 844 & 0 & 68 & 1059 & 847 & 0 & 51 & 983 \\
\cline { 2 - 11 } & 208 & 844 & 0 & 32 & 938 & 844 & 0 & 1 & 846 \\
\cline { 2 - 11 } & 212 & 844 & 0 & 8 & 865 & 844 & 0 & 0 & 844 \\
\cline { 2 - 11 } & 220 & 844 & 0 & 0 & 844 & 844 & 0 & 0 & 844 \\
\cline { 2 - 10 } & 230 & 844 & 0 & 0 & 844 & 844 & 0 & 0 & 844 \\
\cline { 2 - 10 } & 240 & 844 & 0 & 0 & 844 & 844 & 0 & 0 & 844 \\
\cline { 2 - 10 } & 260 & 844 & 0 & 0 & 844 & 844 & 0 & 0 & 844 \\
\cline { 2 - 10 } & 300 & 844 & 0 & 0 & 844 & 844 & 0 & 0 & 844 \\
\cline { 2 - 9 } & 400 & 844 & 0 & 0 & 844 & 844 & 0 & 0 & 844 \\
\hline
\end{tabular}

a - represents infeasible solution.

In Table 4, no improvement can be seen over the yard capacity of 56,000 TEU or over the gate capacity of 300 entries per hour, which correspond to $67 \%$ and $108 \%$ of the quay capacity respectively. This means, if the terminal is managed with the integrated model, there is no need to further invest on any yard capacity bigger than 56,000 TEU or any gate capacity bigger than 300 entries per hour. Therefore, from the practical perspective, our integrated model can be a useful tool to design a better tactical plan by coordinating BAP, SSAP and TAM. On the other hand, it is able to identify the lower and the upper bounds of the yard capacity and the gate capacity for a given demand scenario.

It is interesting to compare the components between the integrated model and the sequential model to understand the interaction between three sub-planning problems. Taking the instances with the yard capacity of 40,000 TEU as example, Table 5 gives more detailed results from two models. In Table $5, \mathrm{z} 1$ is total vessel turn time (in hours) from the BAP sub-plan in the integrated planning model; z2 is total vessel delay (in hours) caused by the SSAP sub-plan in the integrated planning model; z3 is total vessel delay (in hours) caused by the gate congestion from the TAM sub-plan in the integrated planning model; $\mathrm{Z}$ is total vessel turn time from the whole plan in the integrated planning model. While z1', z2', z3' and Z' are the correspondent results from the sequential planning model.

Table 5 compares the solutions from the integrated model and the corresponding 'nominal' best solution from the

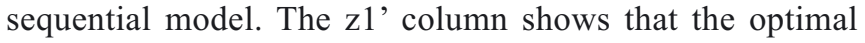
berth plan obtained from the BAP sub-model in the sequential planning model contributes 844 hours to the total vessel turn time. From z2' column, we can see that the SSAP sub-model does not cause vessel delay in these instances, because the yard capacity is big enough to satisfy the storage requirements in the plan. The SSAP sub-model also defines a range for the starting point of each time window as an input of the next sub-model. Under this range constraint, the TAM sub-model 


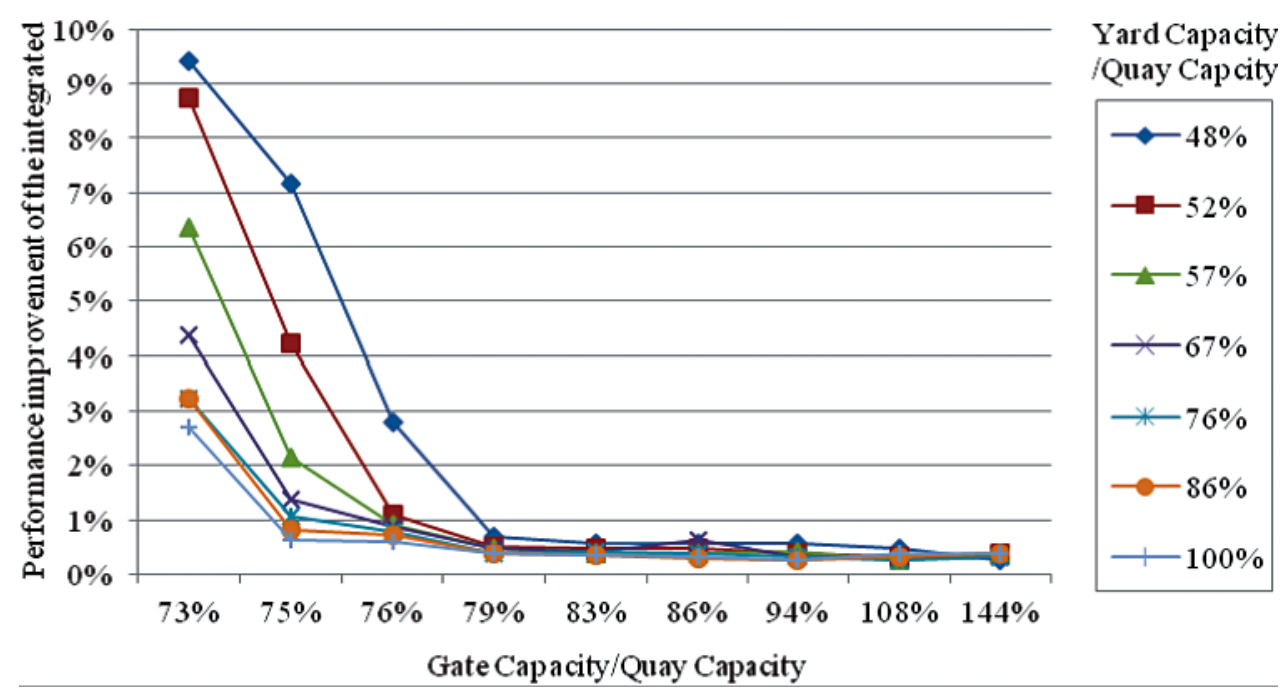

Fig. 12. Improvement percentage of the integrated model from the sequential model

tries to reduce the gate congestion, which sometimes leads to vessel delay as shown in z3' column. A vessel delay may also delay the following vessel if there is not sufficient gap between the handling operations of the two vessels. Too large vessel delay may lead to an infeasible overall solution, for example the instance with the gate capacity of 200 entries per hour. Comparing the columns of the integrated model with the ones of the sequential model, we can see that although the berth plan z1 may incur more berthing time than $\mathrm{zl}$ ' in some instances, e.g. the instance with the gate capacity of 204 entries per hour, the total vessel turn time of the overall plan $\mathrm{Z}$ from the integrated model is smaller than Z'. In conclusion, the integrated planning model can balance the BAP plan and the TAM plan to reach a better overall plan.

The results in Table 3 and Table 4 indicate that the relative merits of the integrated planning model depend on the yard capacity and the gate capacity. In practice, it is quite often that the ratio of the yard capacity to the quayside handling capacity and the ratio of the gate capacity to the quayside handling capacity are of interest because terminal operators are seeking a reasonable balance between these processes. We therefore display the percentage of performance improvement achieved by the integrated model from the sequential model in Fig. 12, in which the horizontal axis represents the ratio of the gate capacity to the quayside capacity, and the vertical axis represents the performance improvement. The performance improvement in each instance is calculated based on the best solution from the integrated planning model and the average value of the top 20 solutions from the sequential planning model. Only the instances in which both the integrated and the sequential models find feasible solutions are shown in Fig. 12 , and the instances with the same yard/quay capacity ratio are linked by a line.

Fig. 12 reveals that when the gate/quay ratio is less than $79 \%$, the performance improvement of the integrated model from the sequential model is rather sensitive to both gate/quay ratio and yard/quay ratio, and the sensitivity increases as either gate/quay ratio or yard/quay ratio decreases. It is noted that when the yard/quay ratio is less than $48 \%$, the sequential model is unable to find feasible solution while the integrated model can. When the gate/quay ratio reaches $79 \%$, the integrated planning model is only marginally better than the sequential model (up to $1 \%$ ). It should be pointed out that this finding is limited to the level of the assumed vessel operation demand, which is $73 \%$ of the quay capacity. Nevertheless, such demand/ quay ratio is reasonable in many container terminals. Otherwise, either the terminal operators may pursue more carriers (to avoid under-utilisation) or carriers may switch to alternative terminals (to avoid over-utilisation and congestion).

With respect to the computational efficiency, the sequential planning model is obviously more competitive against the integrated planning model. A 1,000 generation GA algorithm with 100 populations, taking around 10 minutes on a PC (Intel T7300 Core 2 Duo), is sufficient to find a near optimal solution for all the three sub-models separately in the sequential model. While the integrated model requires a 5,000 generation GA algorithm with 100 populations, which takes three times more computation time on the same PC. The disadvantage of the proposed GA for the integrated model is that if the initial population is poorly generated, the integrated model may not be able to find better solutions than the sequential model. So when the yard capacity and the gate capacity reach a certain level (50\% and $80 \%$ respectively in the above experiment), the sequential model is preferable as it can yield solutions with similar quality with much less computational effort.

\section{CONCLUSIONS}

In marine terminal operations research, there is a growing interest in integration models that are able to find well balanced overall operation plans. This paper addresses an integration model covering the major planning activities at the tactical level, including BAP, SSAP and TAM. A heuristic based GA algorithm is proposed to solve the problem. Through the numerical experiments, it is observed that the integrated planning model performs much better than the sequential planning model alone especially when the yard capacity and the gate capacity are relative low. However, as the yard capacity or the gate capacity increases, the difference is decreasing. The sequential model has the advantage of less computational time.

The managerial implication of this study is that the terminal critical resources should be coordinated through the collaboration with other stakeholders including the seaside customers (e.g. shipping lines) and the landside customers (e.g. shippers) in order to achieve the terminal operation efficiency. The models developed in this study can serve as useful tools to design coordinated plans in terminal management and are able to identify the lower and the upper bounds of the yard capacity and the gate capacity at a container terminal.

This study has the following limitations. First, several practical constraints are not included into the model, including 
the number and efficiency of quay cranes, the operations efficiency of yard cranes, the size of internal trucks and so on. Adding these factors into the model will enable the model to provide more managerial applications, if the problem complexity can be handled. Second, all the cost factors in this model are not analysed, including the cargo storage cost, the truck waiting time cost, the terminal operations cost and the vessel time cost. By including these cost factors, one can make some economic analysis on this topic. Third, the integrated model has only one objective, which is the total ship turn time. But actually there are some more objectives could be considered in this problem, for example the total truck waiting time. There may be some congestion at the gate, which only increases the waiting time of trucks and does not effect on the ship turn time yet. In order to take these related objectives into consideration, we could develop a multi-objective optimization model instead

\section{Appendix A: Sequential Planning Model}

\section{BAP Sub-model}

$$
\min Z=\sum_{i \in I}\left(z_{i}^{w}+z_{i}^{h}\right)
$$

Subject to:

$$
\begin{gathered}
\mathrm{z}_{\mathrm{i}}^{\mathrm{w}}=\max \left(0, \sum_{\mathrm{j} \in \mathrm{J}} \sum_{\mathrm{m} \in \mathrm{I}} \mathrm{x}_{\mathrm{ij}} \mathrm{s}_{\mathrm{mi}}^{\mathrm{j}} \mathrm{T}_{\mathrm{m}}^{\mathrm{c}}-\mathrm{A}_{\mathrm{i}}\right)+\mathrm{w}_{\mathrm{T}_{\mathrm{i}}^{\mathrm{E}}} \forall \mathrm{i} \in \mathrm{I} \\
\mathrm{z}_{\mathrm{i}}^{\mathrm{h}}=\sum_{\mathrm{j} \in \mathrm{J}} \sum_{\mathrm{k} \in \mathrm{K}} \mathrm{x}_{\mathrm{ij}} \mathrm{y}_{\mathrm{ik}}\left(\mathrm{M}_{1}+\frac{\mathrm{V}_{\mathrm{i}}}{\mathrm{H}_{\mathrm{j}}}\right) \quad \forall \mathrm{i} \in \mathrm{I} \\
\mathrm{T}_{\mathrm{i}}^{\mathrm{C}}=\mathrm{A}_{\mathrm{i}}+\mathrm{z}_{\mathrm{i}}^{\mathrm{w}}+\mathrm{z}_{\mathrm{i}}^{\mathrm{h}} \quad \forall \mathrm{i} \in \mathrm{I} \\
\sum_{\mathrm{i} \in \mathrm{I}} \mathrm{x}_{\mathrm{ij}} \mathrm{z}_{\mathrm{i}}^{\mathrm{h}} \leq \mathrm{P} \quad \forall \mathrm{j} \in \mathrm{J} \\
\sum_{\mathrm{j} \in \mathrm{J}} \mathrm{x}_{\mathrm{ij}}=1 \quad \forall \mathrm{i} \in \mathrm{I} \\
\sum_{\mathrm{m} \in \mathrm{I}} \mathrm{s}_{\mathrm{mi}}^{\mathrm{j}} \leq 1 \quad \forall \mathrm{i} \in \mathrm{I}, \forall \mathrm{j} \in \mathrm{J} \\
\sum_{\mathrm{m} \in \mathrm{I} \in \mathrm{I}} \sum_{\mathrm{mi}}^{\mathrm{j}} \mathrm{s}_{\mathrm{mi}}^{\mathrm{j}}=\sum_{\mathrm{i} \in \mathrm{I}} \mathrm{x} \mathrm{x}_{\mathrm{ij}}-1 \quad \forall \mathrm{j} \in \mathrm{J} \\
\mathrm{x}_{\mathrm{ij}} \in\{0,1\} \quad \forall \mathrm{i} \in \mathrm{I}, \forall \mathrm{j} \in \mathrm{J} \\
\forall \mathrm{i} \in \mathrm{I}, \forall \mathrm{m} \in \mathrm{I}, \forall \mathrm{j} \in \mathrm{J}
\end{gathered}
$$

The decision variables of BAP sub-model are $\mathrm{x}_{\mathrm{ij}}$ and $\mathrm{s}_{\mathrm{mi}}$. The objective in Equation (A.1) is the minimization of total vessel turn time. Equation (A.2) calculates the waiting time of each vessel before berthing. Equation (A.3) calculates the expected handling time of each vessel assuming that the related containers are stored in the closest storage zone. Equation (A.4) calculates the expected completion time of each vessel, which is also the expected departure time. Equation (A.5) ensures that the handling workload (hours) of each berth is not over its handling capacity. Equation (A.6) ensures every vessel must be served at some berth. Equation (A.7) and (A.8) ensure that every vessel is scheduled to follow another ship at the same berth, except the first ship. of single objective model, so as to search for solutions with better overall quality.

For future research, we will apply the multi-objective optimization technique to cope with the multi-criteria nature of terminal operation planning. Moreover, investigating more efficient algorithms to improve the search speed for the integrated model is in need. Another research interest is to compare the performance of the integrated model under different assumption settings. In this study it is assumed that a vessel will depart after its handling activities are completed. An alternative in practice is that a vessel always departs on schedule and leaves the late arrived containers in the yard for next vessel to pick up (usually the next week). Considering both cases can produce a more comprehensive understanding of the integrated tactical planning for container terminal operations.

$$
\begin{aligned}
& \mathrm{T}_{\mathrm{i}}^{\mathrm{LS}}=\mathrm{A}_{\mathrm{i}}+\mathrm{z}_{\mathrm{i}}^{\mathrm{w}}-\max \left(\mathrm{M}_{2}, \frac{\mathrm{V}_{\mathrm{i}} \mathrm{r}_{\mathrm{i}}}{\mathrm{fG}}\right) \quad \forall \mathrm{i} \in \mathrm{I} \\
& \mathrm{e}_{\mathrm{ti}}=\left\{\begin{array}{l}
1, \text { if } \mathrm{t} \in\left[\mathrm{T}_{\mathrm{i}}^{\mathrm{LS}}, \mathrm{T}_{\mathrm{i}}^{\mathrm{C}}\right] \\
0, \text { others }
\end{array} \forall \mathrm{i} \in \mathrm{I}, 1 \leq \mathrm{t} \leq \mathrm{P}\right. \\
& \sum_{\mathrm{k} \in \mathrm{K}} \mathrm{y}_{\mathrm{ik}}=1 \quad \forall \mathrm{i} \in \mathrm{I} \\
& \sum_{\mathrm{i} \in \mathrm{I}} \mathrm{y}_{\mathrm{ik}} \mathrm{V}_{\mathrm{i}} \mathrm{r}_{\mathrm{i}} \mathrm{e}_{\mathrm{ti}} \leq \mathrm{B}_{\mathrm{k}} \quad \forall \mathrm{k} \in \mathrm{K}, 1 \leq \mathrm{t} \leq \mathrm{P} \\
& \mathrm{y}_{\mathrm{ik}} \in\{0,1\} \quad \forall \mathrm{i} \in \mathrm{I}, \forall \mathrm{k} \in \mathrm{K}
\end{aligned}
$$

Subject to:$$
\text { SSAP Sub-model }
$$$$
\min \sum_{\mathrm{i} \in \mathrm{I}} \sum_{\mathrm{j} \in \mathrm{J}} \sum_{\mathrm{k} \in \mathrm{K}} \mathrm{x}_{\mathrm{ij}} \mathrm{y}_{\mathrm{ik}} \mathrm{d}_{\mathrm{jk}} \mathrm{V}_{\mathrm{i}} \mathrm{r}_{\mathrm{i}}
$$

The SSAP sub-model has two tasks. The first task is to minimize the total container transport distances between vessel berthing locations and the correspondent container storage locations, as shown in Equation (A.11). The decision variable of the first task is $y_{i k}$, and one of the inputs $x_{i j}$ is obtained from the BAP sub-model. Equation (A.12) calculates the latest starting point of each time window, i.e $\mathrm{T}_{\mathrm{i}}^{\mathrm{LS}}$, based on the information from the BAP sub-model. Equation (A.13) is used to mark the time points that are covered by a time window. Equation (A.14) ensures every vessel must be allocated a storage space. Equation (A.15) ensures at any time step, the total storage demand in a storage zone does not exceed the storage capacity.

$$
\max \sum_{\mathrm{i} \in \mathrm{I}}\left(\mathrm{T}_{\mathrm{i}}^{\mathrm{C}}-\mathrm{T}_{\mathrm{i}}^{\mathrm{ES}}\right) \mathrm{V}_{\mathrm{i}} \mathrm{r}_{\mathrm{i}}
$$

Subject to:

$$
\begin{aligned}
& \mathrm{T}_{\mathrm{i}}^{\mathrm{ES}} \in\left[\mathrm{T}_{1}^{\mathrm{c}}-\mathrm{P}, \mathrm{T}_{2}^{\mathrm{c}}-\mathrm{P}, \ldots . ., \mathrm{T}_{\mathrm{I}}^{\mathrm{c}}-\mathrm{P}\right] \quad \forall \mathrm{i} \in \mathrm{I}
\end{aligned}
$$

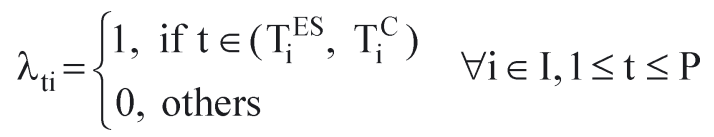

$$
\begin{aligned}
& \sum_{\mathrm{i} \in \mathrm{I}} \mathrm{y}_{\mathrm{ik}} \mathrm{V}_{\mathrm{i}} \mathrm{r}_{\mathrm{i}} \lambda_{\mathrm{ti}} \leq \mathrm{B}_{\mathrm{k}} \quad \forall \mathrm{k} \in \mathrm{K}, 1 \leq \mathrm{t} \leq \mathrm{P}
\end{aligned}
$$

When the storage spaces allocation is done, the second task is to maximize the yard utilization rate, i.e. the number of 
containers multiplied by their longest possible storage time, as shown in Equation (A.17). The decision variable of the second task is the earliest starting point of each time window $\mathrm{T}_{\mathrm{i}}^{\mathrm{ES}}$. Equation (A.18) shows that a $\mathrm{T}_{\mathrm{i}}^{\mathrm{ES}}$ must be set as one of the vessel's handling completion times in the previous period. Equation (A.19) is used to mark the time points when a storage space is occupied by a vessel. Equation (A.20) ensures at any time step, the total storage demand in a storage zone does not exceed the storage capacity.

\section{TAM Sub-Model}

$$
\min \sum_{1 \leq \mathrm{t} \leq \mathrm{P}} \mathrm{q}_{\mathrm{t}}
$$

Subject to:

$$
p_{i t}=\left\{\begin{array}{l}
\int_{d}^{b} u^{0.29}(1-u)^{2.25} d u \\
\int_{0}^{1} u^{0.29}(1-u)^{2.25} d u
\end{array}\right.
$$

where:

$$
\begin{aligned}
& a=\frac{t-T_{i}^{S}}{T_{i}^{E}-T_{i}^{S}}, b=\frac{t-T_{i}^{S}+1}{T_{i}^{E}-T_{i}^{S}} \\
& \text { if: } \\
& \mathrm{t} \in\left[\mathrm{T}_{\mathrm{i}}^{\mathrm{S}}, \mathrm{T}_{\mathrm{i}}^{\mathrm{E}}\right] \\
& \forall \mathrm{i} \in \mathrm{I}, 1 \leq \mathrm{t} \leq \mathrm{P} \\
& \mathrm{N}_{\mathrm{t}}=\sum_{\mathrm{i} \in \mathrm{I}} \frac{\mathrm{p}_{\mathrm{it}} \mathrm{V}_{\mathrm{i}} \mathrm{r}_{\mathrm{i}} \beta}{\mathrm{f}} \quad 1 \leq \mathrm{t} \leq \mathrm{P} \\
& \begin{array}{c}
\mathrm{q}_{\mathrm{t}}=\mathrm{B}-\operatorname{PSFFA}\left(\mathrm{q}_{\mathrm{t}-1}, \mathrm{~N}_{\mathrm{t}}, \mathrm{G}\right) \quad 1 \leq \mathrm{t} \leq \mathrm{P} \\
\mathrm{T}_{\mathrm{i}}^{\mathrm{ES}} \leq \mathrm{T}_{\mathrm{i}}^{\mathrm{S}} \leq \mathrm{T}_{\mathrm{i}}^{\mathrm{LS}} \quad \forall \mathrm{i} \in \mathrm{I}
\end{array}
\end{aligned}
$$

The decision variable is $\mathrm{T}_{i}^{\mathrm{S}}$, and the inputs $\mathrm{T}_{\mathrm{i}}^{\mathrm{E}}, \mathrm{T}_{\mathrm{i}}^{\mathrm{LS}}$ and $\mathrm{T}_{\mathrm{i}}^{\mathrm{ES}}$ are obtained from the above sub-models. The objective is to minimize the total truck waiting time, as shown in Equation (A.21). Given a set of $\mathrm{T}_{i}^{\mathrm{S}}$, Equation (A.22) calculates the probability of a truck related to vessel $i$ arriving at the terminal gate at time step t. Based on $\mathrm{p}_{\mathrm{it}}$, Equation (A.23) calculates the number of trucks arriving at terminal gate at time step $t$. Equation (A.24) estimates the queue length at time step $t$ with the fluid-based B-PSFFA approximation method proposed by Chen et al. (2011c). Equation (A.25) ensures that the actual starting point of a time window must between its earliest and the latest possible starting points.

\section{REFERENCES}

1. Bazzazi, M., Safaei, N., \& Javadian, N. (2009). A genetic algorithm to solve the storage space allocation problem in a container terminal. Computers \& Industrial Engineering, Volume 56, Pages 44-52.

2. Bierwirth, C., \& Meisel, F. (2010). A survey of berth allocation and quay crane scheduling problems in container terminals. European Journal of Operational Research, Volume 202, Pages 615-627.

3. Chang, D., Jiang, Z., Yan, W., \& He, J. (2010). Integrating berth allocation and quay crane assignments. Transportation
Research Part E: Logistics and Transportation Review, Volume 46, Pages 975-990.

4. Chen, G., \& Yang, Z. Z. (2010). Optimizing time windows for managing arrivals of export containers at Chinese container terminals. Maritime Economics \& Logistics, Volume 12, Pages $111-126$.

5. Chen, G., Govindan, K., \& Yang, Z. Z. (2011c). A method to reduce truck queueing at terminal gates: managing truck arrivals with vessel-dependent time windows. Technique Report, Univsersity of Southern Denmark.

6. Chen, G., Govindan, K., \& Yang, Z. Z. (2011b). Designing terminal appointment system with integer programming and non-stationary queueing model. Technique Report, Univsersity of Southern Denmark .

7. Chen, L., \& Lu, Z. (2010). The storage location assignment problem for outbound containers in a maritime terminal. International Journa lof Production Economics, doi:10.1016/ j.ijpe.2010.09.019.

8. Chen, X., Zhou, X., \& List, G. F. (2011a). Using time-varying tolls to optimize truck arrivals at ports. Transportation Research Part E: Logistics and Transportation Review, Volume 47, Pages 965-982.

9. Cordeau, J.-F., Gaudioso, M., Laporte, G., \& Moccia, L. (2007). The service allocation problem at the Gioia Tauro Maritime Terminal. European Journal of Operational Research, Volume 176, Issue 2, Pages 1167-1184.

10.Cordeau, J.-F., Laporte, G., Legato, P., \& Moccia, L. (2005). Models and Tabu search heuristics for the berth-allocation problem. Transportation Science, Volume 39, Pages 526-538.

11.de Oliveira, R.M., Mauri, G.R., \& Lorena L.A. (2012). Clustering Search for the Berth Allocation Problem. Expert Systems with Applications, Volume 29, Issue 5, Pages 54995505.

12.Gangji, S.R.S., Babazadeh, A., \& Arabshahi, N. (2010). Analysis of the continuous berth allocation problem in container ports using a genetic algorithm. Journal of Marine Science and Technology. Volume 15, Number 4, Pages 408-416

13.Geoffrion, A. M. (1999). Structured modelling: survey and future research directions. Interactive Transactions of ORMS

14.Giallombardo, G., Moccia, L., Salani, M., \& Vacca, I. (2010). Modeling and solving the Tactical Berth Allocation Problem. Transportation Research Part B, Volume 44, Issue 2, Pages 232245.

15.Guan, C. Q., \& Liu, R. f. (2009). Container terminal gate appointment system optimization. Maritime Economics \& Logistics, Volume 11, Issue 4, Pages 378-398.

16.Guan, Y., \& Cheung, R. K. (2004). The berth allocation problem: models and solution methods. OR Spectrum, Volume 26, Number 1, Pages 75-92.

17.Han, X.-1., Lu, Z.-q., \& Xi, L.-f. (2010). A proactive approach for simultaneous berth and quay crane scheduling problem with stochastic arrival and handling time. European Journal of Operational Research, Volume 207, Pages 1327-1340.

18.Imai, A., Chen, H. C., Nishimura, E., \& Papadimitriou, S. (2008). The simultaneous berth and quay crane allocation problem. Transportation Research Part E: Logistics and Transportation Review, Volume 44, Pages 900-920.

19.Imai, A., Nishimura, E., \& Papadimitriou, S. (2003). Berth allocation with service priority. Transportation Research Part B, Volume 37, Issue 5, Pages 437-457.

20.Imai, A., Nishimura, E., \& Papadimitriou, S. (2001). The dynamic berth allocation problem for a container port. Transportation Research Part B, Volume 35, Issue 4, Pages 401417.

21.Imai, A., Sun, X., Nishimura, E., \& Papadimitriou, S. (2005). Berth allocation in a container port: using a continuous location space approach. Transportation Research Part B, Volume 39, Issue 3, Pages 199-221.

22.Kim, K. H., \& Kim, H. B. (1999). Segregating space allocation models for container inventories in port container terminals. International Journal of Production Economics, Volume 59, Pages 415-423. 
23.Kim, K. H., \& Park, K. T. (2003). A note on a dynamic spaceallocation method for outbound containers. European Journal of Operational Research, Volume 148, Pages 92-101.

24.Lee, L. H., Chew, E. P., Tan, K. C., \& Han, Y. (2007). An optimization model for storage yard management in transshipment hubs. OR Spectrum, Volume 28, Pages 539-561.

25.Meisel, F. (2009). Seaside operations planning in container terminals. Berlin: Physica-Verlag.

26.Meisel, F., \& Bierwirth, C. (2005). Integration of berth allocation and crane assignment to improve the resource utilization at a seaport container terminal. Operations Research Proceedings (pp. 105-110). Berlin: Springer.

27.Moorthy, R., \& Teo, C.-P. (2006). Berth management in container terminal:the template design problem. OR Spectrum, Volume 28, Issue 4, Pages 495-518.

28.Park, Y., \& Kim, K. (2003). A scheduling method for berth and quay cranes. OR Spectrum, Volume 25, Pages 1-23.

29.Stahlbock, R., \& Voß, S. (2008). Operations research at container terminals: a literature update. OR Spectrum, Volume 30, Number 1, Pages1-52.

30.Steenken, D., Voß, S., \& Stahlbock, R. (2004). Container terminal operation and operations research - a classification and literature review. OR Spectrum, Volume 26, Number 1, Pages 3-49.

31.Taleb-Ibrahimi, M., Castilho, B. d., \& Daganzo, C. F. (1993). Storage space vs handling work in container terminals. Transportation Research Part B: Methodological, Volume 27, Pages 13-32.

32.Vis, I. F., \& Koster, R. d. (2003). Transshipment of containers at a container terminal: An overview. European Journal of Operational Research, Volume 147, Pages 1-16.

33.Woo, Y. J., \& Kim, K. H. (2011). Estimating the space requirement for outbound container inventories in port container terminals. International Journal of Production Economics, Volume 133, Pages 293-301.
34.Yang, Z. Z., Chen, G., \& Moodie, D. R. (2010). Modelling Road Traffic Demand of Container Consolidation in a Chinese Port Terminal. Journal of Transportation Engineering-ASCE, Volume 136, Page 881-886.

35.Zhang, C., Liu, J., Wan, Y.-w., Murty, K. G., \& Linn, R. J. (2003). Storage space allocation in container terminals. Transportation Research Part B: Methodological, Volume 37, Pages 883-903.

\section{CONTACT WITH THE AUTHORS}

Zhong-Zhen Yang*, Ph.D., Professor Transportation Management College, Dalian Maritime University, CHINA

Gang Chen, Ph.D., Assistant Professor Department of Mechanics and Production,

Aalborg University, DENMARK

Dong-Ping Song, Ph.D., Professor School of Management, Plymouth University, the UNITED KINGDOM

* Corresponding author: Zhong-Zhen Yang. Tel.: +86-411-84726756; Fax: +86-411-84726756;

Addr.: Linghai 1, Gangjingzi District, Dalian, CHINA e-mail addresses: clenchen@gmail.com (Chen G.); yangzhongzhen@263.net (Yang Z.Z.); dongping.song@plymouth.ac.uk (Song, D.P.) 